\title{
REVIEW ARTICLE OPEN The role of GPCRs in bone diseases and dysfunctions
}

\author{
Jian Luo $\mathbb{D}^{1}$, Peng Sun ${ }^{1,2}$, Stefan Siwko ${ }^{3}$, Mingyao Liu ${ }^{1,3}$ and Jianru Xiao ${ }^{4}$
}

The superfamily of G protein-coupled receptors (GPCRs) contains immense structural and functional diversity and mediates a myriad of biological processes upon activation by various extracellular signals. Critical roles of GPCRs have been established in bone development, remodeling, and disease. Multiple human GPCR mutations impair bone development or metabolism, resulting in osteopathologies. Here we summarize the disease phenotypes and dysfunctions caused by GPCR gene mutations in humans as well as by deletion in animals. To date, 92 receptors ( 5 glutamate family, 67 rhodopsin family, 5 adhesion, 4 frizzled/taste 2 family, 5 secretin family, and 6 other 7TM receptors) have been associated with bone diseases and dysfunctions (36 in humans and 72 in animals). By analyzing data from these 92 GPCRs, we found that mutation or deletion of different individual GPCRs could induce similar bone diseases or dysfunctions, and the same individual GPCR mutation or deletion could induce different bone diseases or dysfunctions in different populations or animal models. Data from human diseases or dysfunctions identified 19 genes whose mutation was associated with human BMD: 9 genes each for human height and osteoporosis; 4 genes each for human osteoarthritis (OA) and fracture risk; and 2 genes each for adolescent idiopathic scoliosis (AIS), periodontitis, osteosarcoma growth, and tooth development. Reports from gene knockout animals found 40 GPCRs whose deficiency reduced bone mass, while deficiency of 22 GPCRs increased bone mass and BMD; deficiency of 8 GPCRs reduced body length, while 5 mice had reduced femur size upon GPCR deletion. Furthermore, deficiency in 6 GPCRs induced osteoporosis; 4 induced osteoarthritis; 3 delayed fracture healing; 3 reduced arthritis severity; and reduced bone strength, increased bone strength, and increased cortical thickness were each observed in 2 GPCR-deficiency models. The ever-expanding number of GPCR mutation-associated diseases warrants accelerated molecular analysis, population studies, and investigation of phenotype correlation with SNPs to elucidate GPCR function in human diseases.

Bone Research (2019)7:19; https://doi.org/10.1038/s41413-019-0059-6

\section{INTRODUCTION}

Bone development and bone remodeling are processes primarily governed by osteoblast, osteoclast, and chondrocyte differentiation and activity. Fetal bone development proceeds through two courses, intramembranous ossification (typical in flat bone formation) and endochondral ossification (primarily in long bones). Intramembranous ossification is largely influenced by mesenchymal cell differentiation into mature osteoblasts, ${ }^{1}$ while endochondral ossification is driven by mesenchymal cell differentiation into chondrocytes, which then undergo hypertrophy. ${ }^{2}$ Bone remodeling occurs throughout life and involves resorption of mature bone tissue by osteoclasts, which differentiate from hematopoietic cell precursors, ${ }^{3,4}$ and new bone tissue formation by osteoblasts, which arise from mesenchymal stem cells (MSCs) ${ }^{5,6}$ (Fig. 1). Each cell type is regulated by assorted hormones and paracrine factors. These factors determine the relative rates of bone formation and resorption, processes whose homeostasis is critical to prevent bone structure damage, and consequent metabolic bone diseases. ${ }^{7}$

G protein-coupled receptors (GPCRs) are the most numerous transmembrane (TM) protein family implicated in multiple biological processes, including bone development and remodeling $^{8,9}$ vision, $^{10}$ taste, $^{11}$ smell, ${ }^{12}$ neurotransmitter signaling, ${ }^{13}$ inflammation/immune response, ${ }^{14}$ autonomic nervous system regulation, ${ }^{15}$ homeostasis maintenance, ${ }^{16}$ and tumor growth and metastasis. ${ }^{17}$ Because GPCRs play important roles in physiological and pathological processes, have easily targeted ligand-binding domains, and bind diverse chemical modulators, they comprise the most important class of drug targets, accounting for $12 \%$ of all human protein drug targets and the therapeutic effects of approximately $34 \%$ of clinically used drugs. ${ }^{18,19}$ Certain GPCRs and their signaling pathways are responsible for bone homeostasis, and disruption or mutation of these GPCRs results in human bone diseases or dysfunctions, ${ }^{20-29}$ the majority of whose phenotypes have been validated in mouse models. ${ }^{8,30-43}$ Therefore, GPCRs are necessary for regulating bone development and remodeling.

More than 800 human GPCRs (approximately 2\%-3\% of all human genes) have been identified that share common structural motifs. Approximately 150 putative human GPCRs have still unknown functions with unknown ligands and are consequently

\footnotetext{
${ }^{1}$ East China Normal University and Shanghai Changzheng Hospital Joint Research Center for Orthopedic Oncology, Shanghai Key Laboratory of Regulatory Biology, Institute of Biomedical Sciences and School of Life Sciences, East China Normal University, 200241 Shanghai, China; ${ }^{2}$ The Key Laboratory of Adolescent Health Assessment and Exercise Intervention of the Ministry of Education, East China Normal University, 200241 Shanghai, China; ${ }^{3}$ Department of Molecular and Cellular Medicine, Institute of Biosciences and

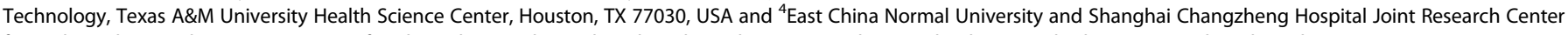
for Orthopedic Oncology, Department of Orthopedic Oncology, Shanghai Changzheng Hospital, Second Military Medical University, Shanghai, China Correspondence: Jian Luo (jluo@bio.ecnu.edu.cn) or Mingyao Liu (myliu@bio.ecnu.edu.cn) or Jianru Xiao (jianruxiao83@163.com)

These authors contributed equally: Jian Luo, Peng Sun
}

Received: 1 January 2019 Revised: 22 May 2019 Accepted: 27 May 2019

Published online: 08 July 2019 


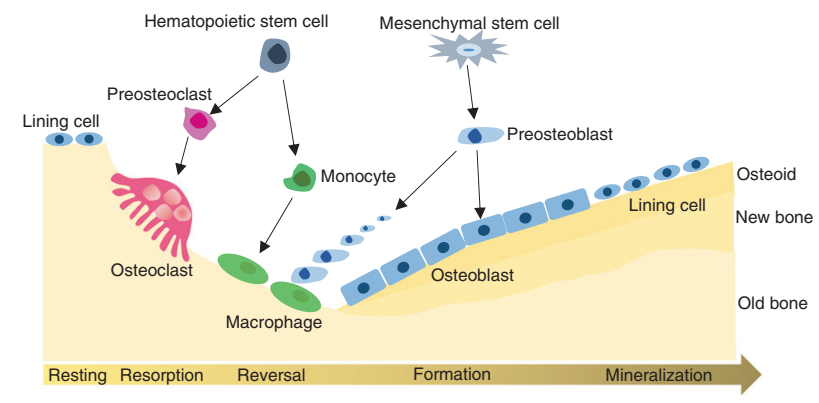

Fig. 1 Bone cells and bone remodeling. Bone is continuously remodeled to maintain tissue integrity. Remodeling begins with old bone resorption by osteoclasts, which differentiate from hematopoietic stem cells. Following resorption, unclassified macrophagelike cells, which are also from hematopoietic stem cells, are found at the remodeling site in the intermediate or reversal phase. Osteoblast precursors, which arise from mesenchymal stem cells, are then recruited and proliferate and differentiate into mature osteoblasts and secrete new bone matrix. The matrix then mineralizes to generate new bone, completing the remodeling process

called orphan receptors. A frequently used GPCR classification system designates classes by letters $A-F$, with subclasses designated with roman numerals. ${ }^{44,45}$ The A-F system was developed from known vertebrate and invertebrate GPCRs. Several groups have no human members; others contain a handful of receptors from only one single class of a species; there are even GPCRs that fail to fit into any of these six groups. Recently, a system that groups human GPCRs into five main families (glutamate $(\mathrm{G})$, rhodopsin $(\mathrm{R})$, adhesion $(\mathrm{A})$, frizzled/taste2 $(F)$, and secretin (S), hence the GRAFS classification system) has been proposed based on phylogenetic analysis. ${ }^{46}$ In this review, we use the GRAFS classification system.

\section{SIGNALING BACKGROUND}

The structural hallmark of GPCRs is the TM helical domain that transverses the cell membrane seven times. Different GPCRs can recognize diverse ligands, including ions, amines, nucleotides, peptides, proteins, lipids, organic odorants, and photons, ${ }^{47}$ normally using an extracellular ligand-binding domain. The cytoplasmic portion of GPCRs possesses a highly dynamic intracellular cleft where signaling partners interact with the receptor. Three families of proteins (heterotrimeric G proteins, GPCR kinases (GRKs), and arrestins) ${ }^{48,49}$ (Fig. 2) are the primary signaling effectors of most GPCRs.

Heterotrimeric $G$ proteins are key transducers of GPCR signaling. ${ }^{50}$ Heterotrimeric $G$ proteins have alpha $(a)$, beta $(\beta)$, and gamma $(\gamma)$ subunits; ${ }^{51} \beta$ and $\gamma$ remain associated throughout the signaling cycle and are referred to as the G $\beta \gamma$ dimer. Alpha (a) $\mathrm{G}$ proteins are allocated to four main classes according to the $\mathrm{Ga}$ sequence: Gas, Gai/o (Gai1-3, GaoA,B, Gaz), Gaq (Gaq, Ga11, $\mathrm{Ga14}, 16)$, and Ga13 (Ga12, Ga13). ${ }^{52,53}$ Inactive G proteins bind GDP with its Ga subunit. GPCR activation conformationally shifts the bound G protein, causing GDP exchange for GTP by the Ga subunit. The GTP-bound Ga subunit then dissociates from the G $\beta \gamma$ dimer (Fig. 2). Free Ga can activate effector molecules, such as adenylyl cyclase (AC). The free $\mathrm{G} \beta \gamma$ dimer can also activate effectors such as potassium channels or phospholipase for downstream signaling. ${ }^{54,55}$

GRKs are included in the AGC kinase family (protein kinases A, $\mathrm{G}$, and C). ${ }^{56}$ GRK family proteins share a common structure featuring a kinase domain in the loop separating a-helices 9 and 10 of the regulatory $G$ protein signaling homology domain. Sequence homology is used to subdivide GRKs into the rhodopsin kinase subfamily (GRK1 and GRK7), the $\beta$-adrenergic receptor kinase subfamily (GRK2 and GRK3), and the GRK4 subfamily (GRK4,

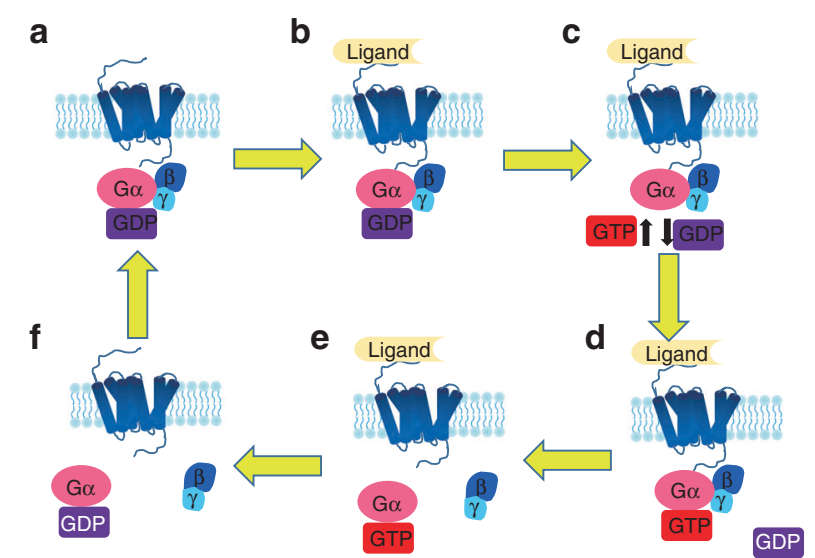

Fig. 2 Activation cycle of $G$ proteins/G protein-coupled receptor (GPCR) upon ligand binding. The receptor in an unbound state is inactive (a), and its coupled G protein is bound to GDP. Ligand binding to its GPCR (b) induces a change in GPCR conformation that promotes GDP exchange for GTP on the heterotrimeric complex $\alpha$ subunit (c, d). Both active, GTP-bound $G \alpha$ and the $G \beta \gamma$ dimer then stimulate downstream effectors (e). When the ligand is no longer bound to the GPCR and the GTP on G $\alpha$ is hydrolyzed to GDP (f), a new inactive GDP-bound heterotrimeric $G$ protein can couple to the GPCR, and the original receptor is restored

GRK5, and GRK6). ${ }^{57}$ GRK 1 and 7 expression is limited to the retina; GRK 2, 3, 5, and 6 are expressed ubiquitously; and GRK4 expression is predominantly observed in the brain, kidney, and testes. ${ }^{58}$ GRKs terminate GPCR activation via phosphorylation of substrate intracellular loops and C-terminal tails. The phosphorylated GPCR then binds arrestins, which exclude $G$ protein interaction and induce receptor-arrestin complex internalization, shutting down signal transduction. ${ }^{59,60}$ Therefore, modulation of GRK protein stability is a potential feedback mechanism for regulating GPCR signaling and basic cellular processes.

Arrestin family proteins regulate GPCR signal transduction ${ }^{61,62}$ by terminating $G$ protein signaling and initiating arrestinmediated GPCR downstream cascades. Mammalian cells express four arrestins: arrestin-1 (also known as visual arrestin), arrestin-2 (also known as $\beta$-arrestin 1), arrestin-3 (also known as $\beta$-arrestin-2), and arrestin-4 (also known as cone arrestin). Arrestin- 1 and arrestin- 4 are selectively expressed in the retina, and arrestin-2 and arrestin- 3 have a broad expression pattern in various cell types. Arrestin-2 and arrestin-3 are $\sim 80 \%$ identical in sequence and have overlapping roles in GPCR regulation. ${ }^{63-66}$

As GPCRs have a variety of signaling modalities that can selectively stimulate (or inhibit) intracellular signaling pathways to treat different diseases by biased signaling, which can minimize the risk of side effects, ${ }^{6,68}$ GPCRs have been major targets of modern therapeutics. For example, the rhodopsin family GPCR Angiotensin II (Angll) type I receptor (AT1R) has been targeted for the treatment of cardiovascular diseases. ${ }^{69,70}$ Recently, AT1R was shown to activate both Gaq signaling and $\beta$-arrestin signaling to exert different functions and side effects. Therefore, the $\beta$-arrestinbiased ligand TRV027 for AT1R is currently in a phase II clinical trial. TRV027 specifically activates AT1R- $\beta$-arrestin signaling (associated with increased cardiomyocyte contractility and cardiac apoptosis prevention) but without stimulating Gaq signaling, which is linked to vasoconstriction and sodium and fluid retention. ${ }^{71,72}$

Multiple GPCRs exhibit bone expression, ${ }^{73}$ and GPCR signaling regulates the proliferation, differentiation, and apoptosis of osteoblasts, osteoclasts, and chondrocytes. ${ }^{6,73-76}$ GPCRs signal through several canonical pathways to regulate osteoblast function ${ }^{77}$ : the $\mathrm{Gs}$ and $\mathrm{Gi}$ pathways regulate $\mathrm{AC}$, increasing or decreasing intracellular cAMP levels, respectively, while Gaq 


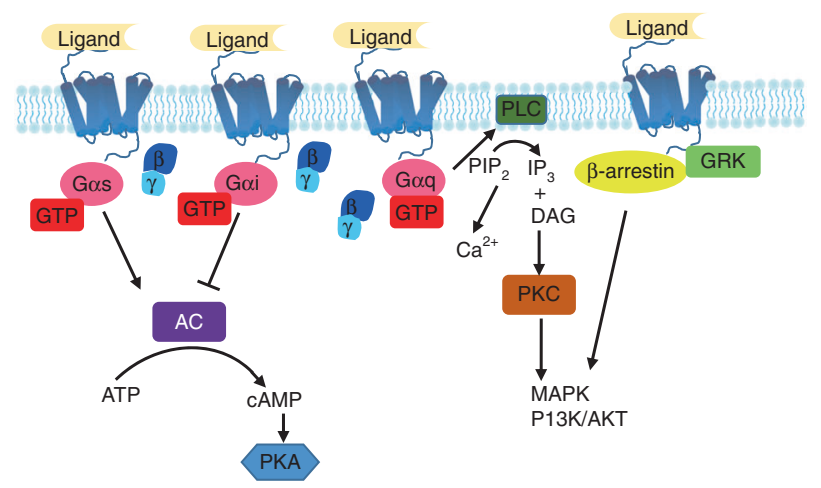

Fig. 3 Major G protein-coupled receptor (GPCR) signaling pathways. GPCR signaling is transduced through several canonical or noncanonical pathways that ultimately proceed through second messengers. The Gs and Gi pathways converge on AC to modulate intracellular cAMP; the Gq pathway increases intracellular $\mathrm{Ca}^{2+}$ and MAPK and PI3K/Akt signals by activating PLC; the $\beta$-arrestin/GRK pathway activates downstream MAPK and PI3K/Akt signals. AC adenylyl cyclase, ATP adenosine triphosphate, CAMP cyclic adenosine monophosphate, PKA protein kinase A, PLC phospholipase C, $\mathrm{PIP}_{2}$ phosphatidylinositol 4,5-bisphosphate, $\mathrm{IP}_{3}$ inositol trisphosphate, DAG diacylglycerol, PKC protein kinase C, MAPK mitogenactivated protein kinase, $\mathrm{PI}_{3} \mathrm{~K}$ phosphoinositide-3-kinase, Akt serinethreonine protein kinase, GRK G protein-coupled receptor kinase

activates phospholipase $C$ (PLC) to increase intracellular calcium. $^{73,78-82}$ In addition, GRK phosphorylation and $\beta$-arrestin signaling govern osteoblast function ${ }^{83-85}$ (Fig. 3). Recent advances have shed light on the mechanisms of osteoclast ${ }^{9,76,86,87}$ and chondrocyte $^{88-92}$ differentiation and function; however, how GPCR signaling regulates osteoclasts and chondrocytes remains largely unknown. The expression of multiple GPCRs by different bone cells and the activation of multiple signaling pathways by a single GPCR, together with the wide variety of GPCRs and the signaling redundancy often seen downstream of GPCR activation, pose significant challenges to clarifying a given GPCR's function in bone development and disease. Nevertheless, incremental advances into the in vivo roles of GPCR signaling pathways and their effects on bone biology have been recently attained (Fig. 2).

\section{DISEASES OR DYSFUNCTION CAUSED BY GPCR MUTATION OR DELETION IN HUMANS AND MICE}

Glutamate family

Glutamate receptors are predominantly expressed by neuronal and glial cells ${ }^{93}$ and transmit glutamate-mediated postsynaptic excitation of neural cells. They regulate neural communication, memory formation, and learning. Several diseases in humans have an established association with glutamate receptor gene mutations, including Parkinson's disease, ${ }^{94}$ Huntington's disease, ${ }^{95}$ ischemic stroke seizures, ${ }^{96}$ attention deficit hyperactivity disorder, ${ }^{97}$ addiction, ${ }^{98}$ and autism. ${ }^{99}$

There are two types of glutamate receptors: metabotropic receptors (mGluRs) bearing a single 7TMD and multimeric ligandgated ion channels, and ionotropic receptors (iGluRs). ${ }^{100}$ The mGluRs are linked to $G$ protein complexes whose associated GTPase activity mediates their signaling. Upon binding glutamate, mGluRs initiate $G$ protein activation as described above, triggering intracellular signaling cascades. ${ }^{101}$ The iGluRs are a composite family, including the kainate (Ka), N-methyl-D-aspartate (NMDA), and a-amino-3-hydroxy-5-methyl-4-isoxazole propionic acid (AMPA) groups. ${ }^{102}$ The different iGluRs have different properties and kinetics, with AMPA and kainates predominantly active in $\mathrm{Na}^{+}$ and $\mathrm{K}^{+}$permeability, while NMDA is predominantly active $\mathrm{Ca}^{2+}$ in permeability. $^{100}$
A variety of glutamate receptors have abundant bone expression and function in bone remodeling. ${ }^{103-107}$ One such receptor is an essential regulator of calcium homeostasis, the calcium-sensing receptor (CASR). Under physiological $\mathrm{Ca}^{+2}$ levels, CASR is activated by extracellular calcium and inhibits parathyroid hormone (PTH) and PTH-related protein (PTHrP) secretion. If systemic calcium levels drop, CASR signaling decreases, allowing PTH and PTHrP secretion, which induces renal retention of $\mathrm{Ca}^{+2}$, increased gut $\mathrm{Ca}^{+2}$ absorption, and eventually elevated bone resorption. ${ }^{108,109}$ Lorentzon et al. found that different CASR alleles are related to bone mineral density (BMD), ${ }^{110}$ and healthy adolescent girls with the $S$ allele have lower BMD than individuals lacking the $S$ allele, and $\mathrm{Di}$ et al. ${ }^{20}$ also verified that the CASR A986S polymorphism increased the risk of osteoporosis in aging males. Knockout of Casr in osteoblasts, driven by $2.3 \mathrm{Col}(\mathrm{I})$-Cre or OSX-Cre, resulted in reducing $B M D$ and bone length to block mouse skeletal development. ${ }^{88}$ Moreover, knockout of Casr, driven by Col(II)-Cre, in chondrocytes blocks embryonic development and cartilage maturation. ${ }^{88}$ Additionally, the mice with global knockout of Casr showed a significantly reduced body length. ${ }^{30}$

Additional phenotypes were validated in mouse models, in which deletion of Gababr1, ${ }^{111}$ Gprc6a, ${ }^{112,113}$ and $G r m 1^{114}$ reduced mouse BMD, while Tas $1 r 3$ deficiency impaired osteoclast function, resulting in reduced bone resorption and increased bone mass. ${ }^{115,116}$ Gababr1-null mice reduce BMD primarily through negatively regulating BMP and upregulating RANKL to affect bone remolding, ${ }^{111}$ while the effects of Gprc6a deletion were primarily caused by defective osteoblast-mediated bone mineralization. ${ }^{112,113}$ Grm1 knockout mice exhibit enhanced bone maturation, marked by premature growth plate fusion, shortened long bones, and lower BMD ${ }^{114}$ (Table 1).

\section{Rhodopsin family}

The rhodopsin family (class $A$ in the A-F classification system), which includes 701 members in humans, is the largest vertebrate GPCR family and regulates many processes throughout the body. Rhodopsin receptors are structurally different from other GPCR subfamilies as they generally possess short $\mathrm{N}$-termini. ${ }^{47}$ The ligands for most rhodopsin receptors, though diverse in structure, typically bind a cavity between the TM regions, ${ }^{117}$ whereas in other GPCR families, the N-terminus plays a key role in ligand binding. Important exceptions exist, particularly the glycoproteinbinding receptors (lutropin, follitropin, and thyrotropin), which bind ligands through an $\mathrm{N}$-terminal domain.

Based on experimental phylogenetic investigation, there are four main groups of rhodopsin GPCRs $(a, \beta, \gamma$, and $\delta)$, which are subdivided into 13 subgroups in humans. ${ }^{46}$ The a-group includes five branches: the prostaglandin, amine, opsin, melatonin, and MECA receptor clusters. The $\beta$-group includes 36 receptors without any main branches. The $\gamma$-group contains three main branches: the SOG, MCH, and chemokine receptor clusters, while the four branches of the $\delta$-group are the MAS-related, glycoprotein, purin, and olfactory receptor clusters. ${ }^{46}$

The rhodopsin family a-group. When the a-group rhodopsin GPCRs were analyzed for effects of mutation or deletion, eight GPCRs were associated with human bone diseases or dysfunctions. Mutations of $A D R B 2,{ }^{118} C N R 2^{21,119,120}$ and DRD4 ${ }^{121,122}$ were associated with reduced human BMD, while $M C 4 R^{123}$ increased BMD. ADRB2 genotypes $\mathrm{AG}$ and $\mathrm{GG}$ had more frequent osteoporosis at the femoral neck (3.27 and 3.89 times more frequent, respectively, compared to AA genotype) in a study of 592 postmenopausal Korean women. ${ }^{118}$ Woo et al. suggested that the CNR2 gene polymorphisms rs2501431, rs3003336, rs2229579, and rs4237 may affect BMD in postmenopausal Korean women. ${ }^{119}$ A CNR2 polymorphism is associated with low BMD in Japanese ${ }^{120}$ and French women. ${ }^{21}$ Japanese men with the $521 \mathrm{C}>$ T polymorphism of DRD4 more frequently had reduced $\mathrm{BMD}$, but no difference 
Table 1. Bone diseases or dysfunctions caused by glutamate GPCR mutation or deletion

\begin{tabular}{|c|c|c|c|}
\hline GABABR1 & Mouse & Reduced BMD & Takahata et al. ${ }^{111}$ \\
\hline GPRC6A & Mouse & Reduced BMD, mineralization, and femur width & $\begin{array}{l}\mathrm{Pi} \text { et } \text { al. }^{112} \\
\mathrm{Pi} \text { et al. }{ }^{113}\end{array}$ \\
\hline TAS1R3 & Mouse & Reduced bone resorption and increased bone mass & $\begin{array}{l}\text { Eaton et al. }{ }^{115} \\
\text { Simon et al. }{ }^{116}\end{array}$ \\
\hline
\end{tabular}

was reported in women. ${ }^{121}$ Five missense mutations (N62S, $\mathrm{R} 165 \mathrm{Q}, \mathrm{V} 253 \mathrm{l}, \mathrm{C} 271 \mathrm{Y}$, and T112M) in MC4R are associated with a marked increase in human BMD and a tendency toward tall height $^{121}$ (Table 2).

DRD2 polymorphism could influence human height in childhood, acting through the hypothalamus (growth hormone (GH)releasing hormone)-pituitary (GH)-Insulin-like growth factor 1 (IFG-1) axis, ${ }^{22}$ while MTNR1B polymorphism was associated with adolescent idiopathic scoliosis (AIS). Moroca et al. found that, compared with CC (MTNR1B) (rs4753426), the risk of AIS significantly increased in Hungarians bearing the CT allele. ${ }^{24}$ Gary et al. reported lower fracture incidence among elderly Swedish women bearing the MC4R C-allele. ${ }^{124}$ Curiously, lipocalin 2, a recently identified ligand of MC4R, is secreted by osteoblasts in mice and signals to suppress appetite by binding MC4Rexpressing hypothalamic neurons ${ }^{125}$; MC4R polymorphisms have also been associated with early-onset obesity. ${ }^{126}$ Mutation of $C N R 2^{21}$ and MTNR1B ${ }^{127}$ had an additional association with human osteoporosis. Karsak et al. found that two missense variants (the double single-nucleotide polymorphism (SNP) rs2502992-rs2501432 and Gln63Arg; rs2229579 and His316Tyr) are associated with osteoporosis in postmenopausal Caucasian women, ${ }^{21}$ while $\mathrm{Li}$ et al. found that MTNR1B rs3781638 is associated with osteoporosis in Chinese geriatrics. ${ }^{127}$ The ADRB2 polymorphism (rs1042714) was also associated with heterotopic ossification in adult trauma patients with fractures. ${ }^{128} E D G 2^{26}$ and $H 4 R^{23}$ were associated with human osteoarthritis (OA) in Japanese people. EDG2 SNPs (rs3739708) affect AP-1 transcriptional activity, which may increase EDG2 expression when the allele is upregulated in knee OA patients, while Yamaura et al. found higher expression of H4R mRNA in synovial tissues from patients with OA (Table 2).

Eighteen a-group GPCR genes have been reported to cause bone dysfunctions when deleted in mouse models. The deletion

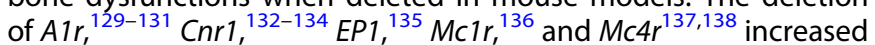
bone mass and BMD, while A2ar, ${ }^{139,140} A 2 b r{ }^{141,142}$ Adrb1, ${ }^{118,143,144}$ Adrb2, ${ }^{143,144}$ Htr2, $^{145-147}$ Lpar1, $^{32,148}$ and $M 3 r^{122}$ reduced bone mass and BMD. A1r, ${ }^{129-131} \mathrm{Cnr} 11^{133}$ and $\mathrm{Mc}^{13 r^{137}}$ knockout mouse bone mass and BMD were significantly increased, accompanied by impaired bone resorption; Mc4r-deficient mice also had higher CART expression, and deleting one CART allele ameliorated the bone resorption phenotype, suggesting that Mc4r function in hypothalamic neurons may regulate osteoclast function, ${ }^{149}$ although direct synovial and bone functions for proopiomelanocortin-derived peptides have been reported. ${ }^{150}$ Deletion of EP1 ${ }^{135}$ increased bone mass and BMD by promoting osteoblast-mediated bone formation. A2ar, ${ }^{139,140} A 2 b r_{1}{ }^{141,142}$ Adrb1, ${ }^{118,143,144}$ Adrb2, ${ }^{143,144}$ Lpar1, $^{32,148}$ and Ep1 ${ }^{135}$ knockout in mice induced bone loss by promoting bone resorption and suppressing bone reformation, while Htr2 deletion suppressed osteoblast recruitment and proliferation and led to osteopenia. ${ }^{147}$ $H$ tr $2^{147}$ and $E p 1^{135}$ also participate in regulating nervous systemmediated bone loss.

The deletion of Cnr2 increased mouse body length by regulating growth plate chondrocyte function, ${ }^{151}$ while Lpar1 reduced body length by regulating osteoblast function. ${ }^{32}$ Furthermore, M3R deletion caused mouse osteoporosis by altering osteoblast and osteoclast function or neuronal regulation, 33,34,122 $\mathrm{H} 4 \mathrm{r}$ deletion accelerated mouse rheumatoid arthritis by promoting osteoclastogenesis, $^{152}$ and Mc1r deficiency caused an articular cartilage phenotype accompanied by accelerated surgically induced murine $\mathrm{OA}^{136}$ Deletion of A3ar promoted mouse osteosarcoma cell proliferation, tumor formation, and metastasis, mainly by activating the protein kinase A (PKA)-Akt-nuclear factor (NF)-KB axis. ${ }^{25}$ Ep1 deletion accelerated fracture repair by enhancing osteoblast differentiation, ${ }^{153}$ and Ep2 deletion reduced mouse bone stiffness, which may be caused by stimulating CAMP formation, an early cellular signal that stimulates bone formation. ${ }^{154}$ Ep4 deletion inhibited mouse bone resorption, though the reason is disputed, with one paper claiming it was a CAMPdependent mechanism ${ }^{155}$ or through proinflammatory cytokines and lipopolysaccharides. ${ }^{155,156} \mathrm{Cnr} 2$ deletion reduced mouse agerelated or ovariectomy-induced bone loss by osteoclast inhibition. ${ }^{157,158}$ Moreover, while Cnr2 knockout reduced bone mass in C57BL/6 mice by regulating osteoblastogenesis and osteoclastogenesis, ${ }^{31,159}$ the opposite phenotype was found in CD1 mice, which had increased bone mass. ${ }^{160}$ These results suggest that different GPCRs have different physiological functions to regulate bone remodeling, and even the same gene may have different physiological functions regulating bone remodeling in different strains of mice (Table 2).

The $\beta$-group of the rhodopsin family. Analysis of the effects of rhodopsin $\beta$-group GPCR mutation or deletion uncovered 10 GPCRs associated with bone diseases or dysfunctions. Of particular interest is the ghrelin receptor, GHSR, whose mutation was associated with reduced human height. ${ }^{27}$ Normally, ghrelin secreted by the stomach induces appetite and regulates lipid metabolism. In 2 families with familial short stature, Pantel and coworkers identified a GHSR missense mutation that downregulated receptor protein levels and selectively impaired GHSR constitutive activity without affecting its response to ghrelin. In Ghsr-deficient mice, a reduction in BMD was caused by impaired bone formation, although the mechanism is disputed. In one report, the phenotype was due to acylated ghrelin signaling and was partially suppressed by unacylated ghrelin ${ }^{161}$; more recently, Gshr re-expression in the osteoblasts, but not in the osteoclasts, of $\mathrm{Gshr}^{-1-}$ mice was able to restore bone formation by promoting osteoblast differentiation. ${ }^{162}$ Additional $\beta$-group rhodopsin GPCRs implicated in human bone disorders, including GNRHRs, ${ }^{28}$ were 


\begin{tabular}{|c|c|c|c|}
\hline \multirow[t]{2}{*}{ A1R } & Mouse & Elevated BMD and bone mass & He et al. ${ }^{129}$ \\
\hline & & & Kara et al. ${ }^{131}$ \\
\hline \multirow[t]{2}{*}{ A2AR } & Mouse & Reduced bone mass and inhibited bone formation & Mediero et al. ${ }^{139}$ \\
\hline & & & Mediero et al. ${ }^{140}$ \\
\hline & & & Carroll et al. ${ }^{142}$ \\
\hline A3AR & Mouse & Promoted osteosarcoma growth & lyer et al. ${ }^{25}$ \\
\hline \multirow[t]{2}{*}{ ADRB1 } & Mouse & Reduced bone mass and BMD & Pierroz et al. ${ }^{143}$ \\
\hline & & & Bonnet et al. ${ }^{144}$ \\
\hline \multirow[t]{2}{*}{ ADRB2 } & Human & SNP associated with reduced BMD, increased risk of fractures, and heterotopic ossification & Lee et al. ${ }^{118}$ \\
\hline & & & Mitchell et al. ${ }^{128}$ \\
\hline CNR1 & & & Khalid et al. ${ }^{134}$ \\
\hline \multirow[t]{9}{*}{ CNR2 } & Human & $\begin{array}{l}\text { The rs } 2501431, \text { rs } 3003336, \text { rs } 2229579 \text {, and rs } 4237 \text { polymorphisms associated with osteoporosis and } \\
\text { decreased BMD }\end{array}$ & Woo et al. ${ }^{119}$ \\
\hline & & & Yamada et al. ${ }^{120}$ \\
\hline & & & Karsak et al. ${ }^{21}$ \\
\hline & Mouse & Reduced bone mass in C57BL/6 background & Ofek et al. ${ }^{31}$ \\
\hline & & & Sophocleous et al. ${ }^{159}$ \\
\hline & & Increased bone mass in CD1 background & Sophocleous et al. ${ }^{160}$ \\
\hline & & Reduced age-related or ovariectomy-induced bone loss & Sophocleous et al. ${ }^{157}$ \\
\hline & & & Idris et al. ${ }^{158}$ \\
\hline & & Increased femoral and vertebral body length & Wasserman et al. ${ }^{151}$ \\
\hline \multirow[t]{2}{*}{ H4R } & Human & Higher expression of H4R mRNA in osteoarthritic patient synovial tissues & Yamaura et al. ${ }^{23}$ \\
\hline & Mouse & Promoted bone destructive process of osteoporosis & Kim et al. ${ }^{152}$ \\
\hline \multirow[t]{3}{*}{ HTR2 } & Mouse & Reduced bone mass and bone formation & Kumar et al. ${ }^{145}$ \\
\hline & & & Yadav et al. ${ }^{146}$ \\
\hline & & & Collet et al. ${ }^{147}$ \\
\hline \multirow[t]{2}{*}{ LPAR1 } & Mouse & Reduced body length and bone mass & Gennero et al. $^{32}$ \\
\hline & & & David et al. ${ }^{148}$ \\
\hline \multirow[t]{3}{*}{ M3R } & Mouse & Induced osteoporosis and reduced BMD & Shi et al. ${ }^{122}$ \\
\hline & & & Lips et al. ${ }^{33}$ \\
\hline & & & Kauschke et al. ${ }^{34}$ \\
\hline M5R & Mouse & Induced osteoporosis & Kauschke et al. ${ }^{34}$ \\
\hline MC1R & Mouse & Increased BMD and bone mass and accelerated osteoarthritis & Lorenz et al. ${ }^{136}$ \\
\hline \multirow[t]{4}{*}{ MC4R } & Human & $\begin{array}{l}\text { Mutations N62S, R165Q, V253I, C271Y, and T112M were associated with increased BMD, and the C allele reduced } \\
\text { fracture risk }\end{array}$ & Farooqi et al. ${ }^{123}$ \\
\hline & & & Gary et al. ${ }^{124}$ \\
\hline & Mouse & Increased BMD, bone mass, and strength & Ahn et al. ${ }^{137}$ \\
\hline & & & Braun et al. ${ }^{138}$ \\
\hline \multirow[t]{2}{*}{ MTNR1B } & Human & CT genotype was associated with AIS and osteoporosis & Moroca et al. ${ }^{24}$ \\
\hline & & & Li et al. ${ }^{127}$ \\
\hline
\end{tabular}


Table 3. Bone diseases or dysfunctions caused by the $\beta$-group of rhodopsin GPCR mutation or deletion

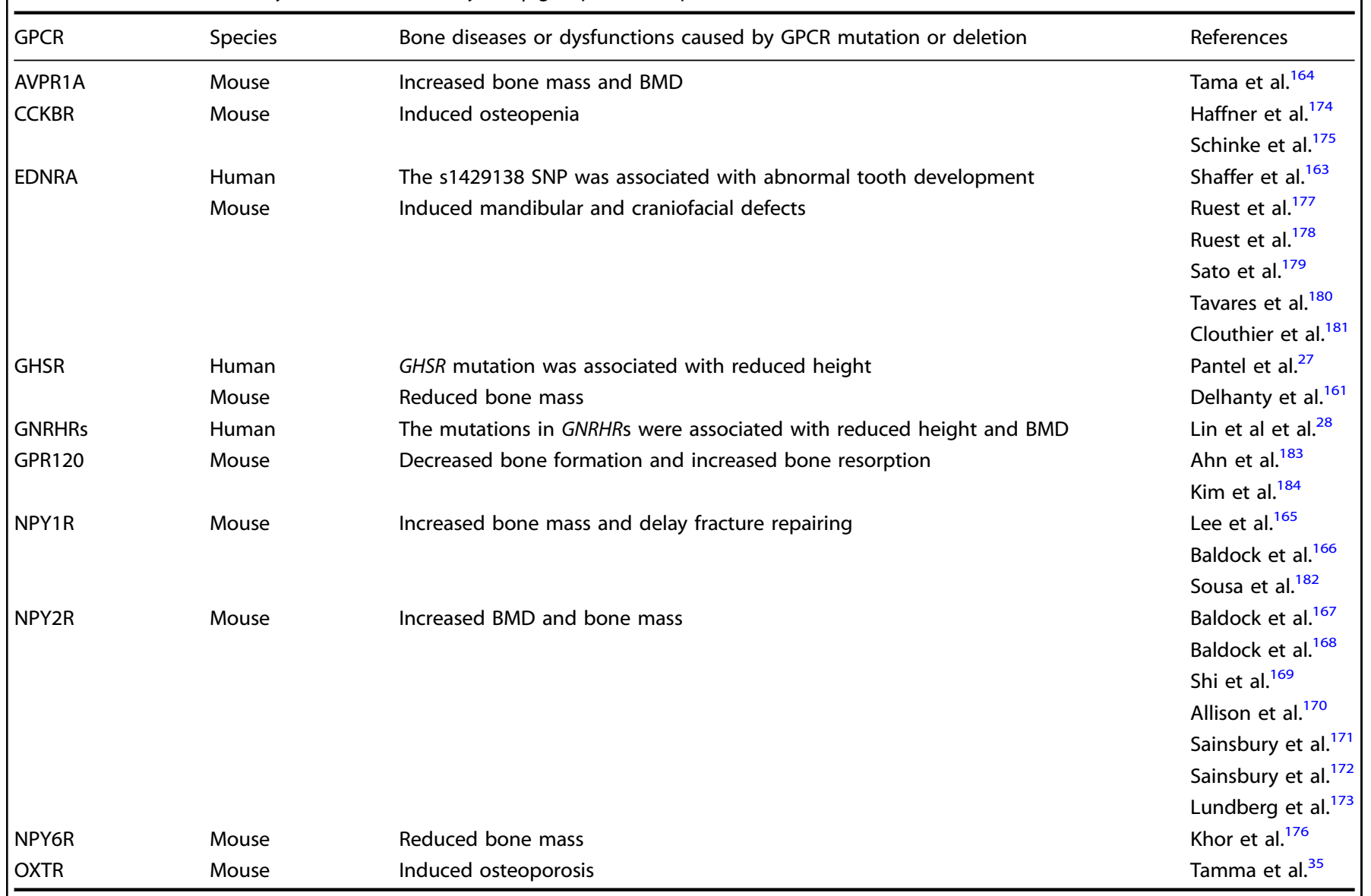

$B M D$ bone mineral density, GPCR G protein-coupled receptor, SNP single-nucleotide polymorphism

associated with reduced human BMD and short stature, and EDNRA was associated with abnormal human tooth development. $^{163}$ Homozygous partial loss-of-function mutations in GNRHRs caused the reduction in height and BMD through delayed puberty or isolated hypogonadotropic hypogonadism. ${ }^{28}$ The EDNRA (rs1429138) gene polymorphism affected gene expression during early craniofacial development and was associated with abnormal human tooth development. ${ }^{163}$

Additional phenotypes were identified in GPCR knockout mouse models. The deficiency of Avpr1a, ${ }^{164} \mathrm{Npy}_{1} r^{165,166}$ and Npy2 $r^{167-173}$ increased mouse bone mass and BMD, while Cckbr, ${ }^{174,175}$ Ghsr $^{161}$ and Npy6r ${ }^{176}$ deficiency reduced bone mass and BMD. Tama et al. reported a dramatic bone mass increase in

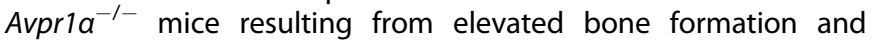
reduced resorption, ${ }^{164}$ while Npy $1 r^{165,166}$ and Npy2 $r^{167-173}$ mice directly regulate osteoblast activity and bone formation; BMD changes occur when these genes are deleted. ${ }^{165}$ In contrast, mice deficient in Cckbr had reduced bone mass and BMD by disrupted calcium homeostasis. ${ }^{174,175}$ Npy6r deletion in mice suppressed osteoblast numbers, osteoid surface area, and bone mineralization while stimulating osteoclast formation and bone resorption, presumably via a suprachiasmatic nucleus relay due to the narrow range of cells that expresses this receptor. ${ }^{176}$ Furthermore, Oxtr deletion caused mouse osteoporosis by inhibiting the differentiation of osteoblasts and stimulating osteoclast formation, ${ }^{35}$ and Ednra deletion caused mouse mandibular and craniofacial defects, possibly by regulating $D / x 5$ and D/x66, which are downstream mediators of Ednra signaling. ${ }^{177-181}$ Fracture repair was delayed while bone callus volume and callus strength decreased in osteoblast-specific Npy1r knockout mice, ${ }^{182}$ and Gpr120 deletion promoted osteoblastic bone formation and negatively regulated osteoclast differentiation, survival, and function ${ }^{183,184}$ (Table 3).

The rhodopsin family $\gamma$-group. Among the $\gamma$-group rhodopsin GPCRs, two GPCR gene polymorphisms were associated with human bone diseases or dysfunctions (Table 4). Eraltan et al. found CCR2 V64I gene polymorphisms in postmenopausal women and demonstrated a positive association of CCR2 Val//le and CCR2 $\mathrm{Val}+$ genotypes with osteoporosis risk. ${ }^{185}$ This polymorphism appears to increase CCR2 protein half-life ${ }^{186}$ and may also be associated with cancer risk and other diseases. ${ }^{186-188}$ Furthermore, Lu and coworkers discovered that three OPRM1 SNPs (rs9479769, rs4870268, and rs1998221) were nominally associated with hip, spine, and whole-body BMD phenotypes in female American Caucasians, potentially via effects on alcohol consumption and/or estrogen signaling. ${ }^{29}$

Fourteen genes from the $\gamma$-group GPCRs have been reported to cause bone dysfunctions in knockout mouse models. The deficiency of $C \times 3 \mathrm{Cr}^{189}$ increased mouse bone mass and BMD by regulating both osteoblasts and osteoclasts, while deficiency of Bdkrb1, ${ }^{190}$ Ccr1, ${ }^{191,192} \mathrm{Ccr6}^{193} \mathrm{Cmklr}^{194}{ }^{194} \mathrm{Cxcr} 2{ }^{36}$ Cxcr4, ${ }^{195}$ Gpr1, ${ }^{196}$ and Gpr54 ${ }^{197}$ reduced bone mass and BMD. Deletion of Bdkrb1 increased mouse bone loss and the number of osteoclasts by increasing differentiation into functional osteoclasts, ${ }^{190}$ and deficiency of $C r r 1^{191,192}$ and Gpr $1^{196}$ caused osteopenia due to decreased osteoclast and osteoblast activity. Doucet et al. ${ }^{193}$ found that $\mathrm{Ccr}^{-/-}$mice exhibited significantly decreased trabecular bone mass and reduced osteoblast numbers. 


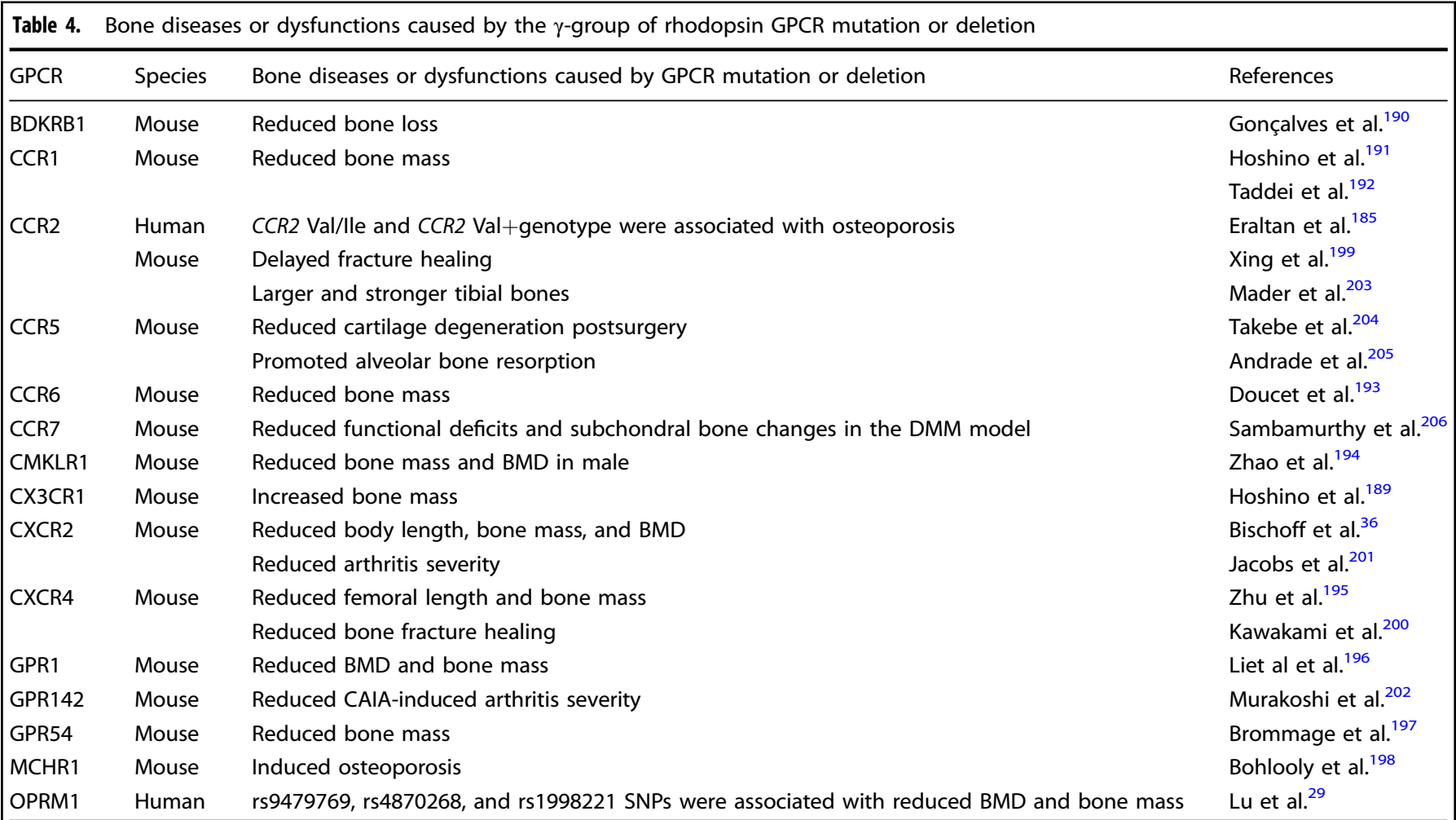

$B M D$ bone mineral density, CAIA collagen antibody-induced arthritis, DMM destabilization of the medial meniscus, GPCR G protein-coupled receptor, SNP single-nucleotide polymorphism

Mechanistic studies indicated that Ccr6 loss delayed osteoblast marker gene expression, inhibited osteoblast differentiation, and reduced mineralization. Zhao et al. ${ }^{194}$ found that $\mathrm{Cmk} / r 1$ deficiency disrupted the balance between osteoblastogenesis and osteoclastogenesis, causing MSCs to shift from osteogenic to adipogenic differentiation and enhancing osteoclast formation and consequently lower bone mass in male mice. Zhu et al. ${ }^{195}$ found that osteoprecursor-specific inactivation of Cxcr4 impaired osteoblast development and reduced postnatal bone formation, leading to a reduction in BMD and femoral length. Conversely, a decrease in BMD and body length in $C x C r 2^{-1-}$ mice occurred despite no alteration in bone formation or bone resorption. ${ }^{36}$ Furthermore, the $\mathrm{Mchr}^{-1-}$ mice have osteoporosis caused by elevated bone resorption resulting in a reduction in the cortical bone mass, while trabecular bone was unaffected. ${ }^{198}$ Ccr2 deficiency reduced macrophage infiltration and impaired osteoclast function, thus delaying bone fracture healing, ${ }^{199}$ while $\mathrm{Cxcr} 4$ knockout mice delayed bone fracture healing by inhibiting osteoblastogenesis. ${ }^{200}$ Cxcr2 knockout mice had attenuated autoantibody-mediated arthritis caused by a function of $\mathrm{Cxcr} 2$ neutrophil recruitment, ${ }^{201}$ while Gpr142 knockout mice showed reduced arthritis scores and disease incidence in an anti-type II collagen antibody-induced arthritis model alongside decreased inflammatory cytokine production. ${ }^{202}$ Mader et al. found that while $\mathrm{Ccr}^{-/-}$mice had larger and stronger bones than wild-type mice, they reported that Ccr2 loss did not significantly protect against bone loss due to disuse or estrogen loss. ${ }^{203}$ Ccr5 deletion was linked to reduced cartilage degeneration postsurgery without significant changes in the degree of synovitis and bone metabolic parameters ${ }^{204}$ and promoted osteoclast function in orthodontic tooth movement. ${ }^{205}$ Furthermore, Ccr7 deletion reduced functional deficits and subchondral bone changes in a surgical destabilization of the medial meniscus model, suggesting that certain chemokine receptors may directly affect nociception ${ }^{206}$ (Table 4).
The $\delta$-group of the rhodopsin family. Five human bone diseases or dysfunctions were associated with eight $\delta$-group rhodopsin GPCR gene polymorphisms. Mutation of LHCGR ${ }^{207-209}$ was associated with reduced human height; FSHR, ${ }^{210}$ RXFP2, $^{211}$ and $T S H R^{212}$ mutations were associated with human osteoporosis; OR2H1 was associated with human $\mathrm{OA}^{213} ; \mathrm{FSHR}_{1}^{210} L G R 4_{1}^{214}$ $R X F P{ }^{215}$ and $T S H R^{216}$ were associated with reduced human $\mathrm{BMD}$, and FPR mutation was associated with juvenile periodontitis (Table 5). Shenker et al. ${ }^{209}$ found eight different families with the same $A>G$ base change that substitutes glycine for aspartate at LHCGR amino acid 578. This mutation elevated cAMP levels when transfected into COS-7 cells, suggesting constitutive luteinizing hormone receptor activation, and was correlated with precocious puberty and increased male height. Rendina et al. ${ }^{210}$ found that women with AA rs6166 (FSHR) had a higher postmenopausal osteoporosis risk than those carrying the GG rs6166 variant, and Ferlin et al. ${ }^{210}$ found that young men with a T222P mutation in RXFP2 were at high risk of osteoporosis, while Liu et al. ${ }^{212}$ suggested that an SNP (C-to-G substitution at codon 727) in TSHR may be an osteoporosis risk factor. Two SNPs in OR2H1 (rs1233490 and rs2746149) were suggestively associated with rheumatoid arthritis phenotypes. ${ }^{213}$ Furthermore, the SNP rs6166 of FSHR significantly influenced postmenopausal female $B M D, 210$ the T222P mutation of RXFP2 was associated with a high risk of reduced young adult $B M D,{ }^{215}$ and the TSHR-Asp727Glu polymorphism was associated with femoral neck BMD in elderly Caucasians. ${ }^{216}$ Finally, two FPR mutations were found in juvenile periodontitis patients: one thymine-to-cytosine substitution at base 329 and the other a cytosine-to-guanine substitution at base $378 .{ }^{217}$

Increasing evidence supports the FSHR subfamily member LGR4 in bone development. In humans, a rare nonsense mutation within LGR4 (c.376C>T) is strongly correlated with diminished $\mathrm{BMD}^{214}$ in accord with similar phenotypes in $\mathrm{Lgr}^{-1-}$ mice. ${ }^{8,9}$ 
Table 5. Bone diseases or dysfunctions caused by the $\delta$-group of rhodopsin GPCR mutation or deletion

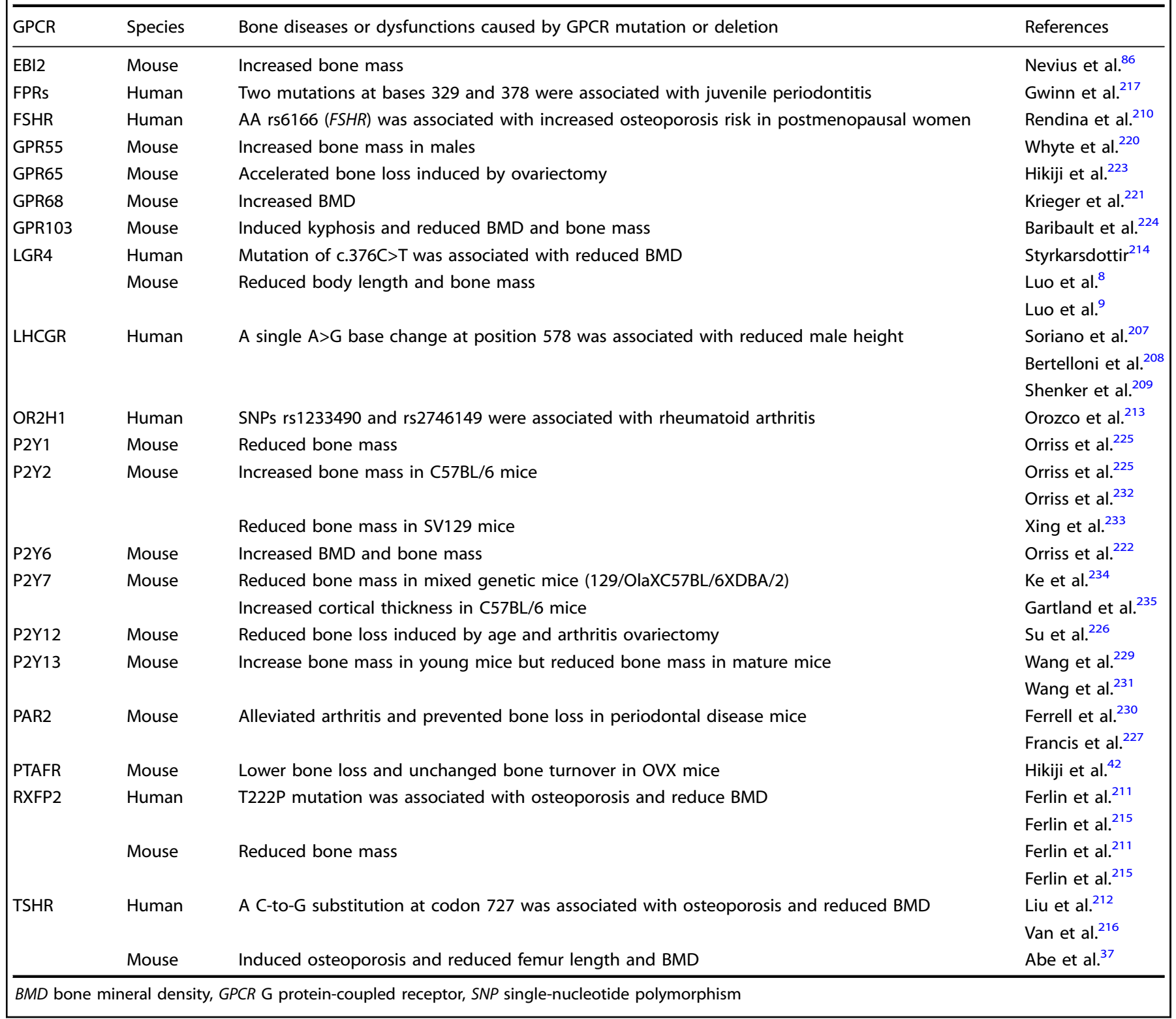

Furthermore, Lgr4 negatively regulates osteoclast differentiation by binding RANKL and downregulating RANK expression in mouse and human cells. ${ }^{9}$ In vitro studies support Lgr4 regulation of osteoblasts and bone MSCs. ${ }^{8,218}$ Mice treated with the Lgr4 extracellular domain to inhibit Lgr4 signaling had lower osteoporosis induced by RANKL injection or ovariectomy, ${ }^{9,219}$ suggesting this GPCR as a potentially valuable therapeutic target in several bone diseases.

Deletion of $16 \delta$-group GPCR genes caused bone dysfunctions in mouse models: deficiency of Ebi2, ${ }^{86} \mathrm{Gpr} 55,{ }^{220} \mathrm{Gpr} 68,{ }^{221} \mathrm{P}_{2 y} \sigma^{222}$ and Ptafr ${ }^{42}$ increased mouse bone mass and BMD; while Gpr65, ${ }^{223}$ Gpr103, ${ }^{224}$ Lgr4, $^{8,9}$ P2y1 $^{225}$ Rxfp2, $^{211,215}$ Tshr $^{37}$ reduced bone mass and $\mathrm{BMD}$; and $P 2 y 12^{-1-}$ mice had reduced age-associated bone loss with lower osteoblast activity, ${ }^{226}$ while deletion of Par2 ${ }^{227}$ bone prevented periodontal disease in mice. Defective Ebi2 signaling suppressed osteoclast precursor cell migration to bones, which led to increased male mouse bone mass and protection of female mice from osteoporosis due to age or estrogen

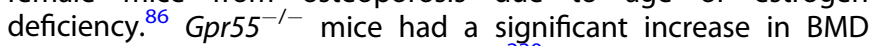
due to stimulated osteoclast function, ${ }^{220}$ and BMD was increased in $G p r 68^{-1-}$ mice by increasing bone turnover and a shift toward increased bone formation over resorption. ${ }^{221}$ The long bones and spine in $P 2 \mathrm{ybr}^{-1-}$ mice exhibited increased bone mineralization, cortical bone volume, and cortical thickness caused by suppressing osteoclastogenesis, whereas trabecular bone parameters were unaffected. ${ }^{222}$ Hikiji et al. ${ }^{42}$ found that Pafr knockout suppressed bone resorption, thus preventing bone loss in ovariectomized (OVX) mice. In contrast, Gpr65 $5^{-1-}$ mice had elevated OVX-induced bone loss induced with enhanced osteoclast formation and osteoclastic calcium resorption. ${ }^{223} \mathrm{Gpr}_{103^{-1-}}$ mice had lower trabecular bone density, possibly from suppressing osteoblast-mediated bone formation, and the kyphosis phenotype was also found in Gpr103 knockout female mice. ${ }^{224}$ $P 2 y 1$ deletion reduced mouse BMD in part through increasing osteoclast formation and activity via ATP and ADP. ${ }^{225,228}$ Rxfpdeficient mice presented with lower bone mass and a reduction in bone turnover via disrupted regulation of osteoblastogenesis and osteoclastogenesis. ${ }^{211,215}$ The BMD reduction in $\mathrm{Tshr}^{-1-}$ mice was caused by altering the regulation of both bone formation and resorption. ${ }^{37}$ Keratinocyte-specific deletion of Par2 prevented 
periodontal bone loss by suppressing the inflammatory cascade, ultimately inhibiting osteoclast differentiation and activity. ${ }^{227} \mathrm{Tshr}$ knockout mice only reduced femur length, ${ }^{37}$ while $P 2 y 13^{-1-}$ mice had increased tibia and tail length, ${ }^{229}$ and Par2 deletion alleviated mouse arthritis. ${ }^{230}$

Furthermore, several GPCR gene knockout mice displayed different phenotypes in different strains. The bone mass was reduced in young (4-week-old) P2y13-knockout mice via promotion of osteoblastogenesis and suppression of osteoclastogenesis, but mature (>10-week-old) P2y13-knockout mice showed the opposite bone phenotype via suppression of osteoblastogenesis. ${ }^{229,231}$ P2y2 deficiency increased mouse bone mass in C57BL/6 mice 225,232 by promoting bone reformation and suppressing bone resorption but exhibited reduced bone mass in SV129 mice ${ }^{233}$ by reducing osteoblast differentiation and mineralization. P2y7 knockout reduced bone mass in mixed genetic mice (129/ OlaXC57BL/6XDBA/2) by reducing osteoblast number and activity ${ }^{234}$ but increased cortical thickness in C57 mice ${ }^{235}$ promoting osteoclast-mediated bone resorption (Table 5).

\section{Adhesion family}

The adhesion GPCR family, including 33 human and 31 mouse $\mathrm{GPCRs}^{236}$ (also referred to as family $\mathrm{B}^{45}, \mathrm{~B} 2{ }^{237}$ EGF-TM7 receptors, ${ }^{238}$ or the LNB-TM7 family ${ }^{239}$ ), is the second largest subgroup of GPCRs. The adhesion GPCRs are divided into nine distinct subfamilies that share typical adhesion GPCR features. ${ }^{240}$ The nine subfamilies are ADGRL (latrophilins), ADGRA, ADGRC (CELSRs), ADGRD, ADGRG, ADGRV (GPR98), ADGRE (EGF-TM7), $A D G R F$, and $A D G R B(B A / s){ }^{236}$ Adhesion GPCRs typically have an extensive $\mathrm{N}$-terminal extracellular region featuring various domains that interact with the extracellular environment to execute adhesive functions. ${ }^{241}$ Each receptor subfamily has a specific combination of domains in its $\mathrm{N}$-terminal extracellular region. Receptors within a subfamily have differing numbers of domain repeats, with consequent variation in their $\mathrm{N}$-terminal extracellular region. ${ }^{241}$

A feature unique to adhesion family GPCRs is their autoproteolytic cleavage at the GPCR proteolysis site, ${ }^{242,243}$ which occurs in the conserved GPCR autoproteolysis-inducing (GAIN) domain. ${ }^{244,245}$ Autoproteolysis splits the highly glycosylated Nterminal fragment (NTF) from the membrane-spanning C-terminal fragment (CTF), which contains the canonical 7TM domain and the intracellular domain. The extracellular NTFs function similar to adhesion proteins, while CTFs activate intracellular signaling cascades. ${ }^{240}$ Adhesion GPCRs are essential components in developmental processes. ${ }^{246}$ Human adhesion GPCR mutations take part in nervous, bone, and cardiovascular disorders and cancers of all major tissues. ${ }^{247-249}$

Analysis of human adhesion GPCR SNPs revealed four GPCRs that were associated with human bone diseases or dysfunctions. However, only two adhesion GPCR knockout animal models with bone phenotypes have been reported. The mutation of GPR126 was associated with alterations in AIS, $^{248,250-253}$ human height, ${ }^{253-257}$ arthrogryposis multiplex congenital, ${ }^{258}$ and aggressive periodontitis. ${ }^{259} \mathrm{Xu}$ et $\mathrm{al}^{252}$ found that three intronic SNPs of GPR126 (rs6570507, rs7774095, and rs7755109) were significantly associated with AIS in Chinese populations, and Kou et al. ${ }^{253}$ also found that rs6570507 was the most significantly linked SNP to AIS in Japanese and European ancestry populations. Liu et al. found that SNPs rs6570507, rs3748069, and rs4896582 were associated with human height in Australian twin families, ${ }^{256}$ and rs6570507 was also correlated with trunk length in a European GWAS metaanalysis. ${ }^{257}$ Ravenscroft et al. ${ }^{258}$ found that a missense substitution (p. Val769Glu [c.2306T>A]) impaired GPR126 autoproteolytic cleavage, resulting in reduced peripheral nerve myelination, possibly causing severe arthrogryposis multiplex congenital, and Kitagaki et al.'s study ${ }^{259}$ in the Japanese population found that the GPR126 SNP rs536714306 impairs signaling and BMP2, ID2, and
ID4 expression, negatively influences periodontal tissue, and leads to aggressive periodontitis, suggesting that bearers have an elevated risk for aggressive periodontitis. High GPR56 expression is correlated with positive rheumatoid factor levels in rheumatoid arthritis patients ${ }^{260}$ and with the proliferation and invasion capacity of osteosarcoma cells. ${ }^{261}$ Liu et al. found that knockdown of GPR110 can decrease human osteosarcoma cell proliferation, migration, and invasion capacity, suggesting a role of GPR110 in tumor progression and possible value as a novel prognostic biomarker in osteosarcoma. ${ }^{262}$ Finally, Tonjes et al. found that two GPR133 variants (rs1569019 and rs1976930) were linked to adult height in Sorbian individuals, ${ }^{263}$ in accord with a study that reported a microdeletion at $12 \mathrm{q} 24.33$, approximately $171.6 \mathrm{~kb}$ downstream of GPR133, which influences height in the Korean population. ${ }^{264}$

In animal models, cartilage tissue-specific Gpr126 deletion caused idiopathic scoliosis and pectus excavatum accompanied by annulus fibrosis development in the intervertebral discs and increased chondrocyte apoptosis. Gpr126 was postulated to signal via upregulation of Gal3st4 transcription without altering intracellular CAMP. ${ }^{253,265}$ Furthermore, Cd97 deficiency increased mouse bone mass, decreased osteoclast number, ${ }^{266}$ and reduced arthritis $^{267}$ (Table 6).

Frizzled/Taste2 family

The Frizzled/Taste2 receptors span two distinct clusters: the frizzled receptors (11 in both humans and mice) and the TAS2 receptors ( 25 human and 34 mouse). ${ }^{46,268}$ Although obvious receptor similarities between these different branches are lacking, several features that differ from the other four GPCR families are shared among the sequences from this family of GPCRs, for example, IFL in TM2, SFLL in TM5, and SxKTL in TM7. The Frizzled receptors are highly conserved evolutionarily, while Taste2 GPCRs probably rapidly evolved and expanded in number. ${ }^{47}$ The ten Frizzled receptors, FZD1-10, plus $\mathrm{SMOH}$, are conserved in most mammals, with highly similar primary amino acid sequences, making the Frizzled family the most highly conserved GPCR family. ${ }^{269,270}$ Frizzled GPCRs are Wnt receptors that play key roles in organism development, diseases and cell signaling. ${ }^{271-277}$ Frizzled GPCRs have a CRD/FZ or FZ domain with ten conserved cysteines. The TAS2 receptors are not related to the glutamate receptor family's TAS1 receptors. TAS2 receptors have seven hydrophobic regions considered putative TM domains, but their very short $\mathrm{N}$-terminal regions are unlikely to bind ligands. ${ }^{278}$ All 25 functional human TAS2 genes (hT2Rs) are expressed in taste receptor cells of the human gustatory papilla. ${ }^{279}$ DNA polymorphisms in 25 functional hT2R genes are relatively common, featuring a large number of amino acid substitutions. ${ }^{280,281}$

Analysis of the human Frizzled/Taste2 family GPCR SNP revealed three GPCRs that were associated with human bone diseases or dysfunctions, and only three GPCR knockout animal models with bone phenotypes have been reported to date. Two FZD1 promoter SNPs (rs2232157, rs2232158) were linked to femoral neck area BMD in men of African ancestry. ${ }^{282,283}$ FZD6 sequencing revealed homozygosity for a nonsense mutation (c.1750G $>T$ [p. Glu584X] and a missense mutation (c.1531C >T [p. Arg511Cys]) causes isolated autosomal-recessive nail dysplasia. ${ }^{284-286}$ Mutation of frizzled-9 was associated with reduced human BMD. ${ }^{273,287}$

Furthermore, Frojmark et al. reported that approximately $50 \%$ of male $\mathrm{Fzd6^{-1- }}$ mice displayed abnormal claw morphology or lack of claws, potentially by suppressing either WNT-3A-FZD or WNT5A-FZD signaling. ${ }^{284}$ Curiously, this phenotype was absent in female mice. Frizzled-9 knockout induced mouse osteopenia by reducing osteoblast-mediated bone formation ${ }^{288}$ and reduced new bone formation after fractures by disturbing osteoblast function. ${ }^{289}$ Smoh knockout reduced BMD, body length, and bone callus formation by reducing osteogenic differentiation in mice $^{38,290}$ (Table 7). 
Table 6. Bone diseases or dysfunctions caused by adhesion GPCR mutation or deletion

\begin{tabular}{|c|c|c|c|}
\hline GPCR & Species & Bone diseases or dysfunctions caused by GPCR mutation or deletion & References \\
\hline CD97 & Mouse & Increased bone mass reduced arthritis & $\begin{array}{l}\text { Yeon et al. } \\
\text { Hoek et } \text { al. }^{267}\end{array}$ \\
\hline GPR56 & Human & High levels were associated with rheumatoid factor and osteosarcoma proliferation and invasion & $\begin{array}{l}\text { Tseng et al. }{ }^{260} \\
\text { Chen et al. }\end{array}$ \\
\hline GPR110 & Human & Prognostic biomarker in osteosarcoma & Liu et al. ${ }^{262}$ \\
\hline \multirow[t]{5}{*}{ GPR126 } & Human & rs6570507, rs7774095, and rs7755109 SNPs were associated with AIS & $\begin{array}{l}\text { Qin et al. }{ }^{250} \\
\text { lkegawa et al. }{ }^{248} \text { Giampietro }^{251} \\
\text { Xu et al. }{ }^{252} \\
\text { Kou et al. }{ }^{253} \\
\text { Soranzo et al. }\end{array}$ \\
\hline & & rs6570507, rs3748069, and rs4896582 SNPs were associated with reduced height & $\begin{array}{l}\text { Karnik et al. }{ }^{254} \\
\text { Liu et al. }{ }^{256} \\
\text { Soranzo et al. } .^{257}\end{array}$ \\
\hline & & $\begin{array}{l}\text { The missense substitution (p.Val769Glu [c.2306T>A]) may be caused by severe arthrogryposis } \\
\text { multiplex congenita }\end{array}$ & Ravenscroft et al. ${ }^{258}$ \\
\hline & & The rs536714306 SNP was associated with aggressive periodontitis & Kitagaki et al. ${ }^{259}$ \\
\hline & Mouse & Induced idiopathic scoliosis and pectus excavatum & Karner et al. ${ }^{265}$ \\
\hline GPR133 & Human & The rs1569019 and rs1976930 SNPs were associated with adult height & $\begin{array}{l}\text { Kim et al. }{ }^{264} \\
\text { Kim et al. }{ }^{249} \\
\text { Tonjes et al. }{ }^{263}\end{array}$ \\
\hline
\end{tabular}

AIS adolescent idiopathic scoliosis, BMD bone mineral density, GPCR G protein-coupled receptor, SNP single-nucleotide polymorphism

Table 7. Diseases or dysfunctions caused by Frizzled/Taste2 GPCR mutation or deletion

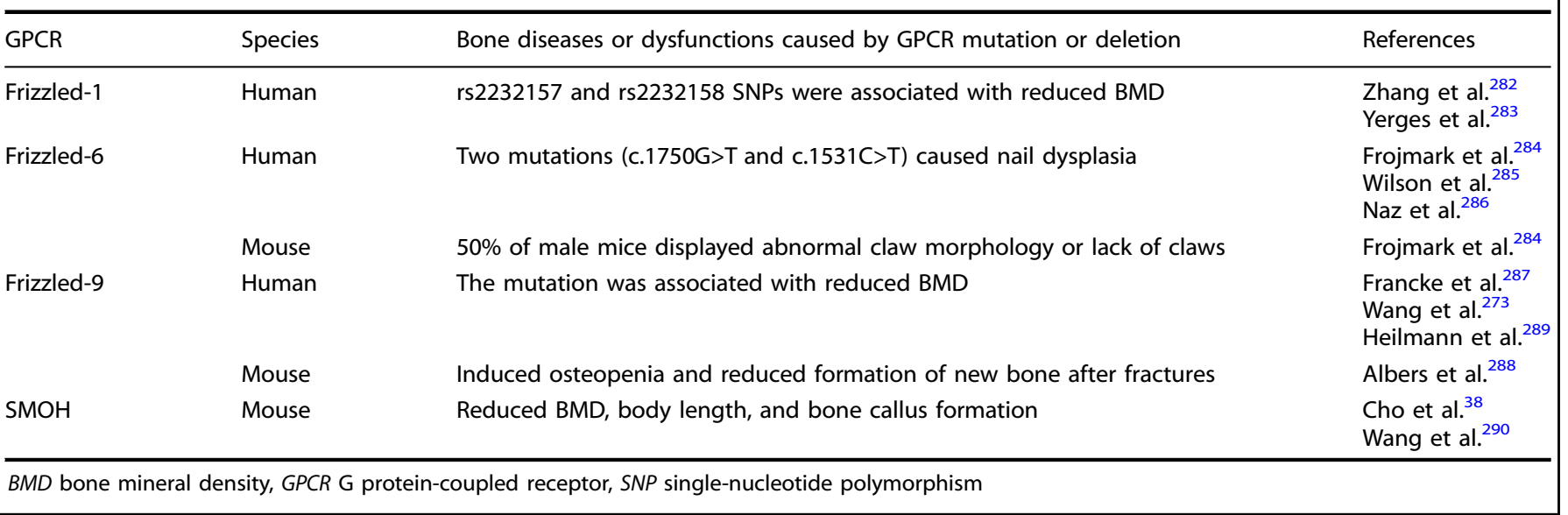

Secretin family

The secretin receptor family has 15 members divided among four subgroups: CRHRs/CALCRLs, PTHRs, GLPRs/GCGR/GIPR, and GHRHR/PACAP/SCTR/VIPR. ${ }^{46}$ These GPCRs are characterized by six conserved $\mathrm{N}$-terminal domain cysteines and by seven conserved TM helices. ${ }^{291-293}$ The $\mathrm{N}$-terminal extracellular domain recognizes the secretin C-terminus, 291,294,295 with the conserved cysteines required for receptor function. ${ }^{296}$ The secretin family GPCRs bind paracrine or endocrine peptide hormones (typically 30-40 amino acids long ${ }^{297}$ ), often indiscriminately. Secretin GPCRs regulate diverse physiological responses, including the cell cycle, differentiation, proliferation, and additional endocrine hormone release. Secretin GPCRs generally signal through $A C$ and to a lesser extent through PLC and intracellular calcium mobilization, although they are not confined to these pathways. ${ }^{298}$ Currently used drugs against osteoporosis, hypercalcemia, Paget's disease, type II diabetes, depression, anxiety, and pancreatic diseases operate by modulating secretin GPCRs.
Five mutations or deletions in secretin family GPCRs were associated with human bone diseases or animal bone dysfunctions. A CALCR SNP was associated with BMD, bone mass, and fracture risk. ${ }^{299-303}$ Multiple reports connected a Pro447Leu (rs1801197) polymorphism of CALCR and osteoporosis-related phenotypes and fracture risk in postmenopausal women, $299,301-306$ and an intronic SNP of rs2051748 was also significantly associated with vertebral trabecular BMD in older Caucasian men. ${ }^{300}$ Zupan et al. found that there was a higher expression of CALCR in osteoarthritic patients. ${ }^{299}$ Furthermore, $\mathrm{CalCr}^{+/-}$mice have a high bone mass with increased bone formation. ${ }^{307}$ Rivadeneira et al. found that the rs9303521 SNP CRHR1 was associated with lumbar spine BMD in people of Northern European descent. ${ }^{308}$ Several studies inferred that the GHRHR SNPs rs17159772, rs4988494, rs2267721, rs4988498, and rs4988505 were associated with reduced human height, indicating that GHRHR might affect normal human height variation. ${ }^{309-312}$ Furthermore, the phenotype of pituitary dwarfism was also observed in individuals with 
Table 8. Bone diseases or dysfunctions caused by secretin GPCR mutation or deletion

GPCR Species Bone diseases or dysfunctions caused by GPCR mutation or deletion

References

CALCR Human SNPs rs1801197 and rs2051748 were associated with BMD and fracture risk; there is a higher expression of Zupan et al. ${ }^{299}$ CALCR in osteoarthritis

Mouse Increased bone mass

CRHR1 Human rs9303521 SNP was associated with BMD

GHRHR Human SNPs rs17159772, rs4988494, rs2267721, rs4988498, and rs4988505 were associated with reduced height

Mutations of IVS1 $+1 \mathrm{G} \rightarrow \mathrm{A}$ or IVS8 $+1 \mathrm{G}>\mathrm{A}$ were associated with dwarfism

GIPR Human SNP rs1800437 was associated with lower BMD and bone mass and increased fracture risk

Mouse Reduced BMD, bone mass, and bone strength and promoted bone resorption

PTHR Human SNPs rs1531137, rs1869872, rs4683301, and rs724449 were associated with reduced height, BMD, and chondrodysplasia

Mouse Reduced body and mouse limb length

Delayed ossification and reduced chondrocyte proliferation and differentiation

Lower trabecular BMD and osteocyte number and increased cortical bone thickness
Zmuda et al. ${ }^{300}$

Lee et al. $^{301}$

Masi et al. ${ }^{302}$

Zofkova et al. ${ }^{303}$

Dacquin et al. ${ }^{307}$

Rivadeneira et al. ${ }^{308}$

Aguiar et al. ${ }^{309}$

Camats et al. ${ }^{310}$

Inoue et ai. ${ }^{311}$

Martari et al. ${ }^{312}$

Wang et al. ${ }^{313}$

Oliveira et al. ${ }^{314}$

Salvatori et al. ${ }^{315}$

Baumann $^{316}$

Baumann et al. ${ }^{317}$

Wajnrajch et al. ${ }^{318}$

Harsloef et al. ${ }^{319}$

Torekov et al. ${ }^{320}$

Xie et al. ${ }^{342}$

Yamada et al. ${ }^{343}$

Mieczkowska et al. ${ }^{40}$

Tsukiyama et al. ${ }^{344}$

Shen et al. ${ }^{345}$

Scillitani et al. ${ }^{321}$

Zhang et al. ${ }^{322}$

Vilarino et al. ${ }^{323}$

Wynne et al. $^{324}$

Schipani et al. ${ }^{325}$

Karaplis et al. ${ }^{326}$

Qiu et al. 329

Lanske et al. ${ }^{327}$

Hirai et al. ${ }^{328}$

Qiu et al. ${ }^{329}$

Guo et al. 330

Lanske et al. ${ }^{39}$

Lanske et al. ${ }^{331}$

Karperien et al. ${ }^{332}$

Hopyan et al. ${ }^{333}$

Qiu et al. ${ }^{335}$

Lanske et al. ${ }^{39}$

Powell et al. ${ }^{334}$

$B M D$ bone mineral density, GPCR G protein-coupled receptor, SNP single-nucleotide polymorphism

GHRHR mutations (IVS1 $+1 \mathrm{G} \rightarrow \mathrm{A}$ or IVS8 $+1 \mathrm{G}>\mathrm{A}$ )..$^{313-318}$ Harsloef et al. and Torekov and colleagues reported that the GIPR polymorphism Glu354GIn (rs1800437) was associated with reduced human BMD and bone mass and increased fracture risk. $^{319,320}$

PTHR is the most extensively studied GPCR in bone development and disease. The PTHR SNPs rs1531137, rs1869872, rs4683301, and rs724449 were associated with reduced human height, ${ }^{321-323} \mathrm{BMD}^{321-324}$ and chondrodysplasia. ${ }^{325,326}$ Consistently, Pthr knockout mice had reduced body length and limbs, ${ }^{327-329}$ reduced trabecular BMD and osteocyte number, delayed ossification, and reduced chondrocyte proliferation and differentiation, ${ }^{39,329-333}$ with increased cortical bone thickness. ${ }^{39,334,335}$ PTH is a systemic hormone that regulates calcium homeostasis and bone remodeling by activating PTHR. ${ }^{329,335}$ It can activate $\mathrm{Gs}$ and $\mathrm{Gq}$, leading to CAMP production, PKA activation 
Table 9. Bone diseases or dysfunctions caused by other 7TM receptor mutations or deletions

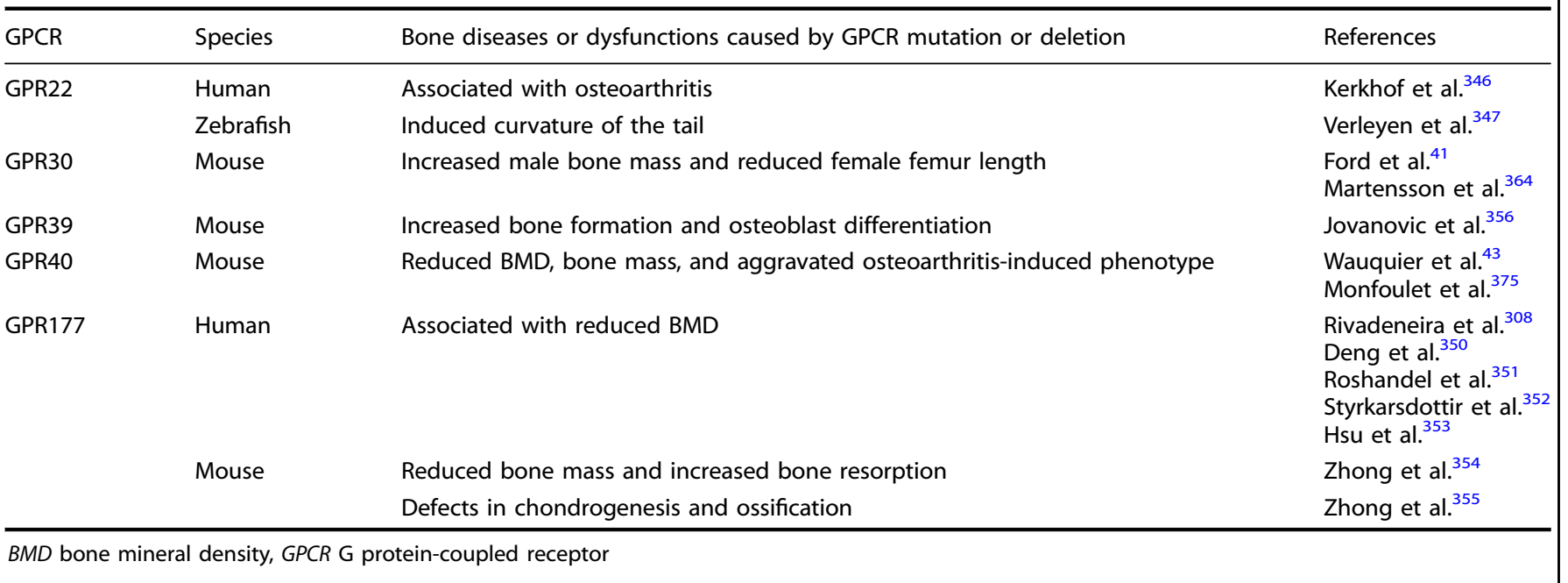

and stimulation of phospholipase for PKC activation to stimulate downstream signaling events. ${ }^{336}$ The 1-34 amino acid peptide of PTH (PTH(1-34)) is an anti-osteoporosis drug that functions by stimulating osteoblast proliferation, ${ }^{337}$ increasing osteoblast activity, ${ }^{338}$ and protecting osteoblasts from apoptosis ${ }^{339}$ through direct binding to PTHR. ${ }^{340}$ Interestingly, PTH(1-34) also maintains intervertebral disc homeostasis during aging, suggesting that PTH has the ability to maintain skeletal homeostasis ${ }^{341}$ (Table 8).

Other 7TM receptors

Several 7TM receptors did not fit into any family/group/cluster of the GRAFS classification system; therefore, these receptors are called other 7TM receptors. Most of them are orphan GPCRs. ${ }^{46,47,268,275}$ There are five genes associated with bone diseases or dysfunctions in humans or mice from the other 7TM receptor group.

GPR22 is an orphan GPCR. In silico and in vitro experiments suggested that the T-alleles of the rs3757713 and rs3815148 SNPs were associated with GPR22 expression in lymphoblasts. GPR22 was detected in cartilage and osteophytes in OA-induced mouse models but not in normal cartilage. Kerkhof et al. ${ }^{346}$ identified SNP rs3815148 (located close to the GPR22 gene) as an OA susceptibility locus in a large association analysis of OA genetics with 14938 OA cases and approximately 39000 controls. Verleyen et al. found that altering the expression of Gpr22 in zebrafish embryos induced a downward-curving tail, which is often associated with defects in ciliogenesis. ${ }^{34} \bar{T}$

GPR177, which is similar to the Frizzled family of GPCRs, is a Wnt signaling pathway component ${ }^{348}$ involved in bone cell differentiation. As part of the RANK pathway, the gene positively regulates the NF-KB cascade. ${ }^{349}$ Several multistage genome-wide association study meta-analyses identified four loci (rs1430742, rs2566755, rs2772300, and rs6588313 SNPs) in GPR177 that were associated with human lumbar spine, femoral neck, or total hip BMD. ${ }^{308,350-353}$ Zhong et al. found that deletion of Gpr177 in mice resulted in bone loss, increased bone resorption, and defects in chondrogenesis and ossification ${ }^{354,355}$ (Table 9).

The deletion of either Gpr30 $0^{41}$ or Gpr39 $9^{356}$ increased bone mass in mice, but in contrast, the deletion of $G p r 40^{43}$ or $G p r 177^{354}$ reduced mouse bone mass and BMD. GPR30, as an estrogen receptor, is activated by estrogen and the GPR30-specific agonist G1. ${ }^{357}$ GPR30 activation elevates cAMP levels, intracellular $\mathrm{Ca}^{+2}$ mobilization, and transactivation of epidermal growth factor receptors. ${ }^{358-361}$ GPR30 expression in human bone is limited to osteoblasts, osteocytes, and osteoclasts. ${ }^{362}$ In immortalized rat skull preosteoblasts, Runx2 upregulated Gpr30 gene expression and increased osteoblast progenitor proliferation, suggesting that Gpr30 may promote osteoblast differentiation. ${ }^{363}$ Confounding this, however, Ford et al. reported that Gpr30 loss increased bone mass, mineralization, and growth plate proliferation in male mice, ${ }^{41}$ whereas Martensson et al. ${ }^{364}$ reported that Gpr30 deletion reduced female mouse femur length.

Gpr39 is a zinc-sensing receptor that is expressed by osteoblast cell lines. ${ }^{365}$ Zinc potently and specifically activates Gpr39 to induce $G q, G 12 / 13$, and Gs pathway signaling, suggesting that zinc is a physiologically important agonist. ${ }^{366}$ Jovanovic et al. ${ }^{356}$ found that Gpr39-deficient mice have higher bone stiffness and a higher mineral-to-matrix ratio, along with increased bone formation and osteoblast differentiation, suggesting that zinc sensing by Gpr39 is important in regulating collagen processing and mineralization, which are required for the proper maintenance of bone integrity.

GPR40 is highly expressed in pancreatic beta cells, where it interacts with medium-to-long chain fatty acids, ${ }^{367-369}$ to potentiate glucose-induced insulin secretion. ${ }^{370}$ GPR40 is also expressed in leukocytes, osteoclasts, and monocytes. ${ }^{371,372}$ Cornish et al. ${ }^{373}$ observed that a GPR40 agonist inhibits osteoclastogenesis, which is similar to the effects of free fatty acids. Furthermore, Gpr40 downregulation protects osteocytes from apoptosis. ${ }^{374}$ Wauquier et al. ${ }^{43}$ observed that $G p r 40^{-1-}$ mice had a reduction in BMD and bone mass with higher promoting osteoclast differentiation, and Monfoulet et al. $^{375}$ observed a more severe OA-induced phenotype in $\mathrm{Gpr}_{40} \mathrm{O}^{-1-}$ mice, marked by elevated tidemark exposure, osteophyte formation, and subchondral bone sclerosis (Table 9).

\section{CONCLUSIONS}

GPCRs play crucial roles in bone development, remodeling, and diseases by activating GPCR signaling pathways. Our results show that 92 receptors ( 5 glutamate family, 67 rhodopsin family, 5 adhesion, 4 frizzled/taste2 family, 5 secretin family, and 6 other 7TM reporters) were associated with bone diseases and dysfunctions ( 35 in humans and 72 in animals), and the catalog of diseases linked to GPCR malfunction continues to expand.

In summary, the GPCR superfamily plays a key role in regulating bone diseases and remodeling. Different GPCRs from different subfamilies may have similar physiological functions to regulate these processes; however, the same GPCR may have different physiological functions in different populations or animal models. Although the field has made significant progress in understanding 
how GPCRs influence bone development and diseases, much remains unknown. Since many GPCR mutations are embryonic lethal, the availability of mouse models to study GPCRs has been a significant barrier to progress. Fortunately, conditional knockout approaches have proven effective in many cases, allowing characterization of the detailed mechanisms involving GPCRs in bone diseases and dysfunctions. This should allow enormous advances in translational medicine, as GPCRs are generally regarded as a superb class of drug targets.

\section{ACKNOWLEDGEMENTS}

This work was supported by grants from the National Key Research and Development Program of China (2018YFC1105102 to J.L., 2016 YFC0902102 to J.L. and J.X.), the National Natural Science Foundation of China (81722020, 91749204, 81472048 to J.L., 81330049 to M.L., 81330059 and 81572640 to J.X.), the Innovation Program of Shanghai Municipal Education Commission (14ZZ051 to J.L., $2017 Z Z 01017$ to J.X.), the Science and Technology Commission of Shanghai Municipality (12ZR1447900 to J.L., 17JC1400903 and 17411950300 to J.X.), and the Fundamental Research Funds for the Central Universities (to J.L.).

\section{ADDITIONAL INFORMATION}

Competing interests: The authors declare no competing interests.

\section{REFERENCES}

1. Ducy, P., Schinke, T. \& Karsenty, G. The osteoblast: a sophisticated fibroblast under central surveillance. Science 289, 1501-1504 (2000).

2. Ornitz, D. M. \& Marie, P. J. FGF signaling pathways in endochondral and intramembranous bone development and human genetic disease. Genes Dev. 16, 1446-1465 (2002)

3. Boyle, W. J., Simonet, W. S. \& Lacey, D. L. Osteoclast differentiation and activation. Nature 423, 337-342 (2003).

4. Teitelbaum, S. L. \& Ross, F. P. Genetic regulation of osteoclast development and function. Nat. Rev. Genet. 4, 638-649 (2003).

5. Huang, W., Yang, S., Shao, J. \& Li, Y. P. Signaling and transcriptional regulation in osteoblast commitment and differentiation. Front. Biosci. 12, 3068-3092 (2007).

6. Keinan, D. et al. Role of regulator of $\mathrm{G}$ protein signaling proteins in bone. Front Biosci. (Landmark Ed.) 19, 634-648 (2014).

7. Jimi, E. et al. The current and future therapies of bone regeneration to repair bone defects. Int. J. Dent. 2012, 148261 (2012).

8. Luo, J. et al. Regulation of bone formation and remodeling by G-protein-coupled receptor 48. Development 136, 2747-2756 (2009).

9. Luo, J. et al. LGR4 is a receptor for RANKL and negatively regulates osteoclast differentiation and bone resorption. Nat. Med. 22, 539-546 (2016).

10. Jastrzebska, B. et al. A G protein-coupled receptor dimerization interface in human cone opsins. Biochemistry 56, 61-72 (2017).

11. Adler, E. et al. A novel family of mammalian taste receptors. Cell 100, 693-702 (2000).

12. Katidou, M., Grosmaitre, X., Lin, J. W. \& Mombaerts, P. G-protein coupled receptors $\mathrm{Mc4r}$ and Drd1a can serve as surrogate odorant receptors in mouse olfactory sensory neurons. Mol. Cell. Neurosci. 88, 138-147 (2018).

13. Grammatopoulos, D. K. Regulation of G-protein coupled receptor signalling underpinning neurobiology of mood disorders and depression. Mol. Cell. Endocrinol. 449, 82-89 (2017).

14. Sharma, N., Akhade, A. S. \& Qadri, A. Sphingosine-1-phosphate suppresses TLRinduced CXCL8 secretion from human T cells. J. Leukoc. Biol. 93, 521-528 (2013).

15. Poole, D. P. \& Bunnett, N. W. G protein-coupled receptor trafficking and signalling in the enteric nervous system: the past, present and future. Adv. Exp. Med. Biol. 891, 145-152 (2016).

16. Hazell, G. G. J. et al. G protein-coupled receptors in the hypothalamic paraventricular and supraoptic nuclei - serpentine gateways to neuroendocrine homeostasis. Front. Neuroendocr. 33, 45-66 (2012).

17. Dorsam, R. T. \& Gutkind, J. S. G-protein-coupled receptors and cancer. Nat. Rev. Cancer 7, 79-94 (2007).

18. Santos, R. et al. A comprehensive map of molecular drug targets. Nat. Rev. Drug Discov. 16, 19-34 (2017).

19. Hauser, A. S., Attwood, M. M., Rask-Andersen, M., Schioth, H. B. \& Gloriam, D. E. Trends in GPCR drug discovery: new agents, targets and indications. Nat. Rev. Drug Discov. 16, 829-842 (2017).

20. Di Nisio, A. et al. Calcium-sensing receptor polymorphisms increase the risk of osteoporosis in ageing males. Endocrine 61, 349-352 (2018).
21. Karsak, M. et al. Cannabinoid receptor type 2 gene is associated with human osteoporosis. Hum. Mol. Genet. 14, 3389-3396 (2005).

22. Miyake, $H$. et al. Allelic variations of the $D 2$ dopamine receptor gene in children with idiopathic short stature. J. Hum. Genet. 44, 26-29 (1999).

23. Yamaura, K., Oda, M., Suzuki, M. \& Ueno, K. Lower expression of histamine H(4) receptor in synovial tissues from patients with rheumatoid arthritis compared to those with osteoarthritis. Rheumatol. Int. 32, 3309-3313 (2012).

24. Morocz, M. et al. Association study of BMP4, IL6, Leptin, MMP3, and MTNR1B gene promoter polymorphisms and adolescent idiopathic scoliosis. Spine (Phila Pa 1976) 36, E123-E130 (2011).

25. Iyer, S. V. et al. Genome-wide RNAi screening identifies TMIGD3 isoform1 as a suppressor of NF-kappaB and osteosarcoma progression. Nat. Commun. 7, 13561 (2016).

26. Mototani, $H$. et al. A functional SNP in EDG2 increases susceptibility to knee osteoarthritis in Japanese. Hum. Mol. Genet. 17, 1790-1797 (2008).

27. Pantel, J. et al. Loss of constitutive activity of the growth hormone secretagogue receptor in familial short stature. J. Clin. Invest. 116, 760-768 (2006).

28. Lin, L. et al. A homozygous $\mathrm{R} 262 \mathrm{Q}$ mutation in the gonadotropin-releasing hormone receptor presenting as constitutional delay of growth and puberty with subsequent borderline oligospermia. J. Clin. Endocr. Metab. 91, 5117-5121 (2006).

29. Lu, S. et al. Bivariate genome-wide association analyses identified genetic pleiotropic effects for bone mineral density and alcohol drinking in Caucasians. J. Bone Miner. Metab. 35, 649-658 (2017).

30. Ho, C. et al. A mouse model of human familial hypocalciuric hypercalcemia and neonatal severe hyperparathyroidism. Nat. Genet. 11, 389-394 (1995).

31. Ofek, O. et al. Peripheral cannabinoid receptor, $C B 2$, regulates bone mass. Proc. Natl Acad. Sci. USA 103, 696-701 (2006).

32. Gennero, I. et al. Absence of the lysophosphatidic acid receptor LPA1 results in abnormal bone development and decreased bone mass. Bone 49, 395-403 (2011).

33. Lips, K. S. et al. Altered ultrastructure, density and cathepsin K expression in bone of female muscarinic acetylcholine receptor M3 knockout mice. Int. Immunopharmacol. 29, 201-207 (2015).

34. Kauschke, V., Lips, K. S., Heiss, C. \& Schnettler, R. Expression of muscarinic acetylcholine receptors M3 and M5 in osteoporosis. Med. Sci. Monit. 20, 869-874 (2014).

35. Tamma, R. et al. Oxytocin is an anabolic bone hormone. Proc. Natl Acad. Sci. USA 106, 7149-7154 (2009).

36. Bischoff, D. S. et al. CXC receptor knockout mice: characterization of skeletal features and membranous bone healing in the adult mouse. Bone 48, 267-274 (2011).

37. Abe, E. et al. TSH is a negative regulator of skeletal remodeling. Cell 115, 151-162 (2003).

38. Cho, E. S., Lim, S. S., Hwang, J. W. \& Lee, J. C. Constitutive activation of smoothened leads to impaired developments of postnatal bone in mice. Mol. Cells 34, 399-405 (2012).

39. Lanske, B. et al. Ablation of the PTHrP gene or the PTH/PTHrP receptor gene leads to distinct abnormalities in bone development. J. Clin. Invest. 104, 399-407 (1999).

40. Mieczkowska, A., Irwin, N., Flatt, P. R., Chappard, D. \& Mabilleau, G. Glucosedependent insulinotropic polypeptide (GIP) receptor deletion leads to reduced bone strength and quality. Bone 56, 337-342 (2013).

41. Ford, J. et al. GPR30 deficiency causes increased bone mass, mineralization, and growth plate proliferative activity in male mice. J. Bone Miner. Res. 26, 298-307 (2011).

42. Hikiji, H., Ishii, S., Shindou, H., Takato, T. \& Shimizu, T. Absence of plateletactivating factor receptor protects mice from osteoporosis following ovariectomy. J. Clin. Invest. 114, 85-93 (2004).

43. Wauquier, F. et al. The free fatty acid receptor $G$ protein-coupled receptor 40 (GPR40) protects from bone loss through inhibition of osteoclast differentiation. J. Biol. Chem. 288, 6542-6551 (2013).

44. Attwood, T. K. \& Findlay, J. B. Fingerprinting G-protein-coupled receptors. Protein Eng. 7, 195-203 (1994).

45. Kolakowski, L. F. Jr. GCRDb: a G-protein-coupled receptor database. Recept. Channels 2, 1-7 (1994).

46. Fredriksson, R., Lagerstrom, M. C., Lundin, L. G. \& Schioth, H. B. The G-proteincoupled receptors in the human genome form five main families. Phylogenetic analysis, paralogon groups, and fingerprints. Mol. Pharmacol. 63, 1256-1272 (2003).

47. Schioth, H. B. \& Fredriksson, R. The GRAFS classification system of G-protein coupled receptors in comparative perspective. Gen. Comp. Endocrinol. 142, 94-101 (2005).

48. Lefkowitz, R. J. The superfamily of heptahelical receptors. Nat. Cell Biol. 2, E133-E136 (2000). 
49. Kobilka, B. K. G protein coupled receptor structure and activation. Biochim. Biophys. Acta 1768, 794-807 (2007).

50. Oldham, W. M. \& Hamm, H. E. Heterotrimeric G protein activation by G-proteincoupled receptors. Nat. Rev. Mol. Cell Biol 9, 60-71 (2008).

51. Hurowitz, E. H. et al. Genomic characterization of the human heterotrimeric $G$ protein alpha, beta, and gamma subunit genes. DNA Res. 7, 111-120 (2000).

52. McCudden, C. R., Hains, M. D., Kimple, R. J., Siderovski, D. P. \& Willard, F. S. Gprotein signaling: back to the future. Cell. Mol. Life Sci. 62, 551-577 (2005).

53. Milligan, G. \& Rees, S. Chimaeric $G$ alpha proteins: their potential use in drug discovery. Trends Pharmacol. Sci. 20, 118-124 (1999).

54. Riddle, E. L., Schwartzman, R. A., Bond, M. \& Insel, P. A. Multi-tasking RGS proteins in the heart: the next therapeutic target? Circ. Res. 96, 401-411 (2005).

55. Wieland, T., Lutz, S. \& Chidiac, P. Regulators of G protein signalling: a spotlight on emerging functions in the cardiovascular system. Curr. Opin. Pharmacol. 7, 201-207 (2007).

56. Homan, K. T. \& Tesmer, J. J. Structural insights into $G$ protein-coupled receptor kinase function. Curr. Opin. Cell Biol. 27, 25-31 (2014).

57. He, Y. et al. Molecular assembly of rhodopsin with $\mathrm{G}$ protein-coupled receptor kinases. Cell Res. 27, 728-747 (2017).

58. Jean-Charles, P. Y., Kaur, S. \& Shenoy, S. K. G. Protein-coupled receptor signaling through beta-arrestin-dependent mechanisms. J. Cardiovasc. Pharmacol. 70, 142-158 (2017).

59. Pitcher, J. A., Freedman, N. J. \& Lefkowitz, R. J. G protein-coupled receptor kinases. Annu. Rev. Biochem. 67, 653-692 (1998).

60. Premont, R. T. \& Gainetdinov, R. R. Physiological roles of G protein-coupled receptor kinases and arrestins. Annu. Rev. Physiol. 69, 511-534 (2007).

61. Lefkowitz, R. J. \& Shenoy, S. K. Transduction of receptor signals by beta-arrestins. Science 308, 512-517 (2005).

62. Moore, C. A., Milano, S. K. \& Benovic, J. L. Regulation of receptor trafficking by GRKs and arrestins. Annu. Rev. Physiol. 69, 451-482 (2007).

63. Kohout, T. A., Lin, F. S., Perry, S. J., Conner, D. A. \& Lefkowitz, R. J. beta-Arrestin 1 and 2 differentially regulate heptahelical receptor signaling and trafficking. Proc. Natl Acad. Sci. USA 98, 1601-1606 (2001).

64. DeWire, S. M., Ahn, S., Lefkowitz, R. J. \& Shenoy, S. K. beta-arrestins and cell signaling. Annu. Rev. Physiol. 69, 483-510 (2007).

65. Srivastava, A., Gupta, B., Gupta, C. \& Shukla, A. K. Emerging functional divergence of beta-arrestin isoforms in GPCR function. Trends Endocrinol. Metab. 26, 628-642 (2015).

66. Gurevich, V. V. \& Gurevich, E. V. Structural determinants of arrestin functions. Prog. Mol. Biol. Transl. Sci. 118, 57-92 (2013).

67. Leach, K., Conigrave, A. D., Sexton, P. M. \& Christopoulos, A. Towards tissuespecific pharmacology: insights from the calcium-sensing receptor as a paradigm for GPCR (patho)physiological bias. Trends Pharmacol. Sci. 36, 215-225 (2015).

68. Kenakin, T. \& Christopoulos, A. Signalling bias in new drug discovery: detection, quantification and therapeutic impact. Nat. Rev. Drug Discov. 12, 205-216 (2013).

69. Dasgupta, C. \& Zhang, L. Angiotensin II receptors and drug discovery in cardiovascular disease. Drug Discov. Today 16, 22-34 (2011).

70. Ferrario, C. M. \& Mullick, A. E. Renin angiotensin aldosterone inhibition in the treatment of cardiovascular disease. Pharm. Res. 125(Pt A), 57-71 (2017).

71. Takezako, T., Unal, H., Karnik, S. S. \& Node, K. Current topics in angiotensin II type 1 receptor research: Focus on inverse agonism, receptor dimerization and biased agonism. Pharmacol. Res. 123, 40-50 (2017).

72. Ikeda, Y., Kumagai, H., Motozawa, Y., Suzuki, J. \& Komuro, I. Biased agonism of the angiotensin II type I receptor. Int. Heart J. 56, 485-488 (2015).

73. Wu, M., Deng, L., Zhu, G. \& Li, Y. P. G Protein and its signaling pathway in bone development and disease. Front. Biosci. (Landmark Ed.) 15, 957-985 (2010).

74. Jules, J., Yang, S., Chen, W. \& Li, Y. P. Role of regulators of G protein signaling proteins in bone physiology and pathophysiology. Prog. Mol. Biol. Transl. Sci. 133, 47-75 (2015).

75. Hsiao, E. C., Millard, S. M. \& Nissenson, R. A. Gs/Gi regulation of bone cell differentiation: review and insights from engineered receptors. Horm. Metab. Res. 48, 689-699 (2016).

76. Diepenhorst, N. et al. G protein-coupled receptors as anabolic drug targets in osteoporosis. Pharm. Ther. 184, 1-12 (2018).

77. Gether, U. Uncovering molecular mechanisms involved in activation of $G$ protein-coupled receptors. Endocr. Rev. 21, 90-113 (2000).

78. Bowler, W. B., Gallagher, J. A. \& Bilbe, G. G-protein coupled receptors in bone. Front. Biosci. 3, d769-d780 (1998).

79. Conklin, B. R. et al. Engineering GPCR signaling pathways with RASSLs. Nat. Methods 5, 673-678 (2008).

80. Kronenberg, H. M. Gs signaling in osteoblasts and hematopoietic stem cells. Ann. NY Acad. Sci. 1192, 327-329 (2010).
81. Saggio, I. et al. Constitutive expression of Gsalpha(R201C) in mice produces a heritable, direct replica of human fibrous dysplasia bone pathology and demonstrates its natural history. J. Bone Min. Res. 29, 2357-2368 (2014).

82. Remoli, C. et al. Osteoblast-specific expression of the fibrous dysplasia (FD)causing mutation Gsalpha(R201C) produces a high bone mass phenotype but does not reproduce FD in the mouse. J. Bone Min. Res. 30, 1030-1043 (2015).

83. Bliziotes, M., Murtagh, J. \& Wiren, K. Beta-adrenergic receptor kinase-like activity and beta-arrestin are expressed in osteoblastic cells. J. Bone Miner. Res. 11, 820-826 (1996).

84. Spurney, R. F. Regulated expression of $G$ protein-coupled receptor kinases (GRK's) and beta-arrestins in osteoblasts. Calcif. Tissue Int. 73, 153-160 (2003).

85. Ferrari, S. L. et al. Bone response to intermittent parathyroid hormone is altered in mice null for beta-arrestin2. Endocrinology 146, 1854-1862 (2005).

86. Nevius, E. et al. Oxysterols and EBI2 promote osteoclast precursor migration to bone surfaces and regulate bone mass homeostasis. J. Exp. Med. 212, 1931-1946 (2015).

87. Masuhara, M. et al. A relation between osteoclastogenesis inhibition and membrane-type estrogen receptor GPR30. Biochem. Biophys. Rep. 8, 389-394 (2016).

88. Chang, W. H., Tu, C., Chen, T. H., Bikle, D. \& Shoback, D. The extracellular calciumsensing receptor (CaSR) is a critical modulator of skeletal development. Sci. Signal. 1, ra1 (2008).

89. James, C. G., Appleton, C. T., Ulici, V., Underhill, T. M. \& Beier, F. Microarray analyses of gene expression during chondrocyte differentiation identifies novel regulators of hypertrophy. Mol. Biol. Cell 16, 5316-5333 (2005).

90. Chagin, A. S. \& Kronenberg, H. M. Role of G-proteins in the differentiation of epiphyseal chondrocytes. J. Mol. Endocrinol. 53, R39-R45 (2014).

91. Chagin, A. S. et al. G-protein stimulatory subunit alpha and Gq/11 alpha Gproteins are both required to maintain quiescent stem-like chondrocytes. Nat. Commun. 5, 3673 (2014).

92. Sakamoto, A., Chen, M., Kobayashi, T., Kronenberg, H. M. \& Weinstein, L. S. Chondrocyte-specific knockout of the $G$ protein $G(s)$ alpha leads to epiphyseal and growth plate abnormalities and ectopic chondrocyte formation. J. Bone Miner. Res. 20, 663-671 (2005).

93. Brassai, A., Suvanjeiev, R. G., Ban, E. G. \& Lakatos, M. Role of synaptic and nonsynaptic glutamate receptors in ischaemia induced neurotoxicity. Brain Res. Bull. 112, 1-6 (2015).

94. Hamza, T. H. et al. Glutamate receptor gene GRIN2A, coffee, and Parkinson disease. PLoS Genet. 10, e1004774 (2014).

95. Wu, J., Tang, T. \& Bezprozvanny, I. Evaluation of clinically relevant glutamate pathway inhibitors in in vitro model of Huntington's disease. Neurosci. Lett. 407, 219-223 (2006).

96. Akins, P. T. \& Atkinson, R. P. Glutamate AMPA receptor antagonist treatment for ischaemic stroke. Curr. Med. Res. Opin. 18(Suppl. 2), s9-s13 (2002).

97. Elia, J. et al. Genome-wide copy number variation study associates metabotropic glutamate receptor gene networks with attention deficit hyperactivity disorder. Nat. Genet. 44, 78-84 (2011).

98. Vadasz, C. et al. Glutamate receptor metabotropic 7 is cis-regulated in the mouse brain and modulates alcohol drinking. Genomics 90, 690-702 (2007).

99. Schmeisser, M. J. et al. Autistic-like behaviours and hyperactivity in mice lacking ProSAP1/Shank2. Nature 486, 256 (2012).

100. Skerry, T. M. \& Taylor, A. F. Glutamate signalling in bone. Curr. Pharm. Des. 7, 737-750 (2001).

101. Aramori, I. \& Nakanishi, S. Signal transduction and pharmacological characteristics of a metabotropic glutamate receptor, mGluR1, in transfected CHO cells. Neuron 8, 757-765 (1992).

102. Rosenmund, C., Stern-Bach, Y. \& Stevens, C. F. The tetrameric structure of a glutamate receptor channel. Science 280, 1596-1599 (1998).

103. Szczesniak, A. M., Gilbert, R. W., Mukhida, M. \& Anderson, G. I. Mechanical loading modulates glutamate receptor subunit expression in bone. Bone 37, 63-73 (2005).

104. Chenu, C., Serre, C. M., Raynal, C., Burt-Pichat, B. \& Delmas, P. D. Glutamate receptors are expressed by bone cells and are involved in bone resorption. Bone 22, 295-299 (1998)

105. Patton, A. J., Genever, P. G., Birch, M. A., Suva, L. J. \& Skerry, T. M. Expression of an $\mathrm{N}$-methyl-D-aspartate-type receptor by human and rat osteoblasts and osteoclasts suggests a novel glutamate signaling pathway in bone. Bone 22, 645-649 (1998).

106. Gilbert, R. W., Szczesniak, A. M., Langman, M. F. \& Anderson, G. I. Variation in expression of glutamate receptor subunits in skeletal tissue with mechanical loading. J. Bone Miner. Res. 14, S489-S489 (1999).

107. Santa Maria, C. et al. Interplay between CaSR and PTH1R signaling in skeletal development and osteoanabolism. Semin. Cell. Dev. Biol. 49, 11-23 (2016).

108. Civitelli, R. \& Ziambaras, K. Calcium and phosphate homeostasis: concerted interplay of new regulators. J. Endocrinol. Invest. 34(7 Suppl.), 3-7 (2011). 
109. Peacock, M. Calcium metabolism in health and disease. Clin. J. Am. Soc. Nephrol. 5(Suppl. 1), S23-S30 (2010).

110. Lorentzon, M., Lorentzon, R., Lerner, U. H. \& Nordstrom, P. Calcium sensing receptor gene polymorphism, circulating calcium concentrations and bone mineral density in healthy adolescent girls. Eur. J. Endocrinol. 144, 257-261 (2001).

111. Takahata, Y. et al. Osteoblastic gamma-aminobutyric acid, type B receptors negatively regulate osteoblastogenesis toward disturbance of osteoclastogenesis mediated by receptor activator of nuclear factor kappaB ligand in mouse bone. J. Biol. Chem. 286, 32906-32917 (2011).

112. Pi, M. et al. GPRC6A null mice exhibit osteopenia, feminization and metabolic syndrome. PLOS ONE 3, e3858 (2008).

113. $\mathrm{Pi}, \mathrm{M}$. et al. Impaired osteoblast function in GPRC6A null mice. J. Bone Miner. Res. 25, 1092-1102 (2010).

114. Musante, I. et al. Phenotypic characterization of Grm1(crv4) mice reveals a functional role for the type 1 metabotropic glutamate receptor in bone mineralization. Bone 94, 114-123 (2017).

115. Eaton, M. S. et al. Loss of the nutrient sensor TAS1R3 leads to reduced bone resorption. J. Physiol. Biochem. 74, 3-8 (2018).

116. Simon, B. R. et al. Sweet taste receptor deficient mice have decreased adiposity and increased bone mass. PLOS ONE 9, 1 (2014).

117. Baldwin, J. M. Structure and function of receptors coupled to $G$ proteins. Curr. Opin. Cell Biol. 6, 180-190 (1994).

118. Lee, H. J. et al. Association between polymorphisms in leptin, leptin receptor, and beta-adrenergic receptor genes and bone mineral density in postmenopausal Korean women. Menopause 21, 67-73 (2014).

119. Woo, J. H., Kim, H., Kim, J. H. \& Kim, J. G. Cannabinoid receptor gene polymorphisms and bone mineral density in Korean postmenopausal women. Menopause 22, 512-519 (2015).

120. Yamada, Y., Ando, F. \& Shimokata, H. Association of candidate gene polymorphisms with bone mineral density in community-dwelling Japanese women and men. Int. J. Mol. Med. 19, 791-801 (2007).

121. Yamada, Y., Ando, F., Niino, N. \& Shimokata, H. Association of a polymorphism of the dopamine receptor D4 gene with bone mineral density in Japanese men. J. Hum. Genet. 48, 629-633 (2003).

122. Shi, $Y$. et al. Signaling through the $M(3)$ muscarinic receptor favors bone mass accrual by decreasing sympathetic activity. Cell. Metab. 11, 231-238 (2010).

123. Farooqi, I. S. et al. Dominant and recessive inheritance of morbid obesity associated with melanocortin 4 receptor deficiency. J. Clin. Invest. 106, 271-279 (2000).

124. Garg, G. et al. Variation in the MC4R gene is associated with bone phenotypes in elderly Swedish women. PLoS ONE 9, e88565 (2014).

125. Mosialou, I. et al. MC4R-dependent suppression of appetite by bone-derived lipocalin 2. Nature 543, 385-390 (2017).

126. MacKenzie, R. G. Obesity-associated mutations in the human melanocortin-4 receptor gene. Peptides 27, 395-403 (2006).

127. Li, Y. et al. Association of osteoporosis with genetic variants of circadian genes in Chinese geriatrics. Osteoporos. Int. 27, 1485-1492 (2016).

128. Mitchell, E. J., Canter, J., Norris, P., Jenkins, J. \& Morris, J. The genetics of heterotopic ossification: insight into the bone remodeling pathway. J. Orthop. Trauma 24, 530-533 (2010).

129. He, W. \& Cronstein, B. The roles of adenosine and adenosine receptors in bone remodeling. Front. Biosci. (Elite Ed.) 3, 888-895 (2011).

130. Kara, F. M. et al. Adenosine $A 1$ receptors (A1Rs) play a critical role in osteoclast formation and function. FASEB J. 24, 2325-2333 (2010).

131. Kara, F. M. et al. Adenosine $A(1)$ receptors regulate bone resorption in mice: adenosine $A(1)$ receptor blockade or deletion increases bone density and prevents ovariectomy-induced bone loss in adenosine $A(1)$ receptor-knockout mice. Arthritis Rheum. 62, 534-541 (2010).

132. Tam, J. et al. Involvement of neuronal cannabinoid receptor $C B 1$ in regulation of bone mass and bone remodeling. Mol. Pharmacol. 70, 786-792 (2006).

133. Idris, A. I. et al. Regulation of bone mass, bone loss and osteoclast activity by cannabinoid receptors. Nat. Med. 11, 774-779 (2005).

134. Khalid, A. B., Goodyear, S. R., Ross, R. A. \& Aspden, R. M. Mechanical and material properties of cortical and trabecular bone from cannabinoid receptor-1-null (Cnr1(-/-)) mice. Med. Eng. Phys. 38, 1044-1054 (2016).

135. Zhang, $M$. et al. Loss of the PGE2 receptor EP1 enhances bone acquisition, which protects against age and ovariectomy-induced impairments in bone strength. Bone 72, 92-100 (2015).

136. Lorenz, J. et al. Melanocortin 1 receptor-signaling deficiency results in an articular cartilage phenotype and accelerates pathogenesis of surgically induced murine osteoarthritis. PLOS ONE 9, e105858 (2014).

137. Ahn, J. D. et al. Cart overexpression is the only identifiable cause of high bone mass in melanocortin 4 receptor deficiency. Endocrinology 147, 3196-3202 (2006).
138. Braun, T. P. et al. Regulation of lean mass, bone mass, and exercise tolerance by the central melanocortin system. PLOS ONE 7, e42183 (2012).

139. Mediero, A., Kara, F. M., Wilder, T. \& Cronstein, B. N. Adenosine A(2A) receptor ligation inhibits osteoclast formation. Am. J. Pathol. 180, 775-786 (2012).

140. Mediero, A., Wilder, T., Perez-Aso, M. \& Cronstein, B. N. Direct or indirect stimulation of adenosine $A 2 A$ receptors enhances bone regeneration as well as bone morphogenetic protein-2. FASEB J. 29, 1577-1590 (2015).

141. Corciulo, C., Wilder, T. \& Cronstein, B. N. Adenosine A2B receptors play an important role in bone homeostasis. Purinergic Signal. 12, 537-547 (2016).

142. Carroll, S. H. et al. A2B adenosine receptor promotes mesenchymal stem cell differentiation to osteoblasts and bone formation in vivo. J. Biol. Chem. 287 15718-15727 (2012).

143. Pierroz, D. D. et al. Deletion of beta-adrenergic receptor 1, 2, or both leads to different bone phenotypes and response to mechanical stimulation. J. Bone Miner. Res. 27, 1252-1262 (2012).

144. Bonnet, N., Pierroz, D. D. \& Ferrari, S. L. Adrenergic control of bone remodeling and its implications for the treatment of osteoporosis. J. Musculoskelet. Neuron. Interact. 8, 94-104 (2008).

145. Kumar, K. K., Tung, S. \& Iqbal, J. Bone loss in anorexia nervosa: leptin, serotonin, and the sympathetic nervous system. Ann. NY Acad. Sci. 1211, 51-65 (2010).

146. Yadav, V. K. et al. A serotonin-dependent mechanism explains the leptin regulation of bone mass, appetite, and energy expenditure. Cell 138, 976-989 (2009).

147. Collet, $\mathrm{C}$. et al. The serotonin $5-\mathrm{HT} 2 \mathrm{~B}$ receptor controls bone mass via osteoblast recruitment and proliferation. FASEB J. 22, 418-427 (2008).

148. David, M. et al. Lysophosphatidic acid receptor type 1 (LPA1) plays a functional role in osteoclast differentiation and bone resorption activity. J. Biol. Chem. 289, 6551-6564 (2014).

149. Ahn, J. D., Dubern, B., Lubrano-Berthelier, C., Clement, K. \& Karsenty, G. Cart overexpression is the only identifiable cause of high bone mass in melanocortin 4 receptor deficiency. Endocrinology 147, 3196-3202 (2006).

150. Bohm, M. \& Grassel, S. Role of proopiomelanocortin-derived peptides and their receptors in the osteoarticular system: from basic to translational research. Endocr. Rev. 33, 623-651 (2012).

151. Wasserman, E. et al. CB1 cannabinoid receptors mediate endochondral skeletal growth attenuation by Delta9-tetrahydrocannabinol. Ann. NY Acad. Sci. 1335, 110-119 (2015)

152. Kim, K. W. et al. Histamine and histamine $\mathrm{H} 4$ receptor promotes osteoclastogenesis in rheumatoid arthritis. Sci. Rep. 7, 1197 (2017).

153. Zhang, M. et al. EP1(-/-) mice have enhanced osteoblast differentiation and accelerated fracture repair. J. Bone Miner. Res. 26, 792-802 (2011).

154. Akhter, M. P., Cullen, D. M., Gong, G. \& Recker, R. R. Bone biomechanical properties in prostaglandin EP1 and EP2 knockout mice. Bone 29, 121-125 (2001).

155. Miyaura, C. et al. Impaired bone resorption to prostaglandin E2 in prostaglandin E receptor EP4-knockout mice. J. Biol. Chem. 275, 19819-19823 (2000).

156. Sakuma, Y. et al. Crucial involvement of the EP4 subtype of prostaglandin E receptor in osteoclast formation by proinflammatory cytokines and lipopolysaccharide. J. Bone Miner. Res. 15, 218-227 (2000).

157. Sophocleous, A., Marino, S., Kabir, D., Ralston, S. H. \& Idris, A. I. Combined deficiency of the $\mathrm{Cnr} 1$ and $\mathrm{Cnr} 2$ receptors protects against age-related bone loss by osteoclast inhibition. Aging Cell 16, 1051-1061 (2017).

158. Idris, A. I., Sophocleous, A., Landao-Bassonga, E., van't Hof, R. J. \& Ralston, S. H. Regulation of bone mass, osteoclast function, and ovariectomy-induced bone loss by the type 2 cannabinoid receptor. Endocrinology 149, 5619-5626 (2008).

159. Sophocleous, A., Landao-Bassonga, E., Van't Hof, R. J., Idris, A. I. \& Ralston, S. H. The type 2 cannabinoid receptor regulates bone mass and ovariectomy-induced bone loss by affecting osteoblast differentiation and bone formation. Endocrinology 152, 2141-2149 (2011).

160. Sophocleous, A., Idris, A. I. \& Ralston, S. H. Genetic background modifies the effects of type 2 cannabinoid receptor deficiency on bone mass and bone turnover. Calcif. Tissue Int. 94, 259-268 (2014).

161. Delhanty, P. J. et al. Genetic manipulation of the ghrelin signaling system in male mice reveals bone compartment specificity of acylated and unacylated ghrelin in the regulation of bone remodeling. Endocrinology 155, 4287-4295 (2014).

162. $\mathrm{Ma}, \mathrm{C}$. et al. Genetic determination of the cellular basis of the ghrelin-dependent bone remodeling. Mol. Metab. 4, 175-185 (2015).

163. Shaffer, J. R. et al. GWAS of dental caries patterns in the permanent dentition. J. Dent. Res. 92, 38-44 (2013).

164. Tamma, R. et al. Regulation of bone remodeling by vasopressin explains the bone loss in hyponatremia. Proc. Natl Acad. Sci. USA 110, 18644-18649 (2013).

165. Lee, N. J. et al. Osteoblast specific $Y 1$ receptor deletion enhances bone mass. Bone 48, 461-467 (2011). 
166. Baldock, P. A. et al. Novel role of $\mathrm{Y} 1$ receptors in the coordinated regulation of bone and energy homeostasis. J. Biol. Chem. 282, 19092-19102 (2007).

167. Baldock, P. A. et al. Hypothalamic Y2 receptors regulate bone formation. J. Clin. Invest. 109, 915-921 (2002).

168. Baldock, P. A. et al. Hypothalamic regulation of cortical bone mass: opposing activity of Y2 receptor and leptin pathways. J. Bone Miner. Res. 21, 1600-1607 (2006).

169. Shi, Y. C. et al. NPY neuron-specific Y2 receptors regulate adipose tissue and trabecular bone but not cortical bone homeostasis in mice. PLOS ONE 5, e11361 (2010).

170. Allison, S. J., Baldock, P. A. \& Herzog, H. The control of bone remodeling by neuropeptide $Y$ receptors. Peptides 28, 320-325 (2007).

171. Sainsbury, A. et al. Synergistic effects of Y2 and Y4 receptors on adiposity and bone mass revealed in double knockout mice. Mol. Cell. Biol. 23, 5225-5233 (2003).

172. Allison, S. J. et al. Conditional deletion of hypothalamic Y2 receptors reverts gonadectomy-induced bone loss in adult mice. J. Biol. Chem. 281, 23436-23444 (2006).

173. Lundberg, P. et al. Greater bone formation of Y2 knockout mice is associated with increased osteoprogenitor numbers and altered $\mathrm{Y} 1$ receptor expression. $\mathrm{J}$. Biol. Chem. 282, 19082-19091 (2007).

174. Haffner-Luntzer, M. et al. Hypochlorhydria-induced calcium malabsorption does not affect fracture healing but increases post-traumatic bone loss in the intact skeleton. J. Orthop. Res. 34, 1914-1921 (2016).

175. Schinke, T. et al. Impaired gastric acidification negatively affects calcium homeostasis and bone mass. Nat. Med. 15, 674-681 (2009).

176. Khor, E. C. et al. They6 receptor suppresses bone resorption and stimulates bone formation in mice via a suprachiasmatic nucleus relay. Bone 84, 139-147 (2016).

177. Ruest, L. B., Kedzierski, R., Yanagisawa, M. \& Clouthier, D. E. Deletion of the endothelin-A receptor gene within the developing mandible. Cell Tissue Res. 319, 447-453 (2005)

178. Ruest, L. B. \& Clouthier, D. E. Elucidating timing and function of endothelin-A receptor signaling during craniofacial development using neural crest cellspecific gene deletion and receptor antagonism. Dev. Biol. 328, 94-108 (2009).

179. Sato, T. et al. An endothelin-1 switch specifies maxillomandibular identity. Proc. Natl Acad. Sci. USA 105, 18806-18811 (2008).

180. Tavares, A. L. et al. Ectodermal-derived Endothelin1 is required for patterning the distal and intermediate domains of the mouse mandibular arch. Dev. Biol. 371, 47-56 (2012).

181. Clouthier, D. E., Garcia, E. \& Schilling, T. F. Regulation of facial morphogenesis by endothelin signaling: insights from mice and fish. Am. J. Med. Genet. A 152A, 2962-2973 (2010).

182. Sousa, D. M. et al. Neuropeptide $Y$ modulates fracture healing through $Y 1$ receptor signaling. J. Orthop. Res. 31, 1570-1578 (2013).

183. Ahn, S. H. et al. Free fatty acid receptor 4 (GPR120) stimulates bone formation and suppresses bone resorption in the presence of elevated $n-3$ fatty acid levels. Endocrinology 157, 2621-2635 (2016).

184. Kim, H. J. et al. G protein-coupled receptor 120 signaling negatively regulates osteoclast differentiation, survival, and function. J. Cell. Physiol. 231, 844-851 (2016).

185. Eraltan, H. et al. MCP-1 and CCR2 gene variants and the risk for osteoporosis and osteopenia. Genet. Test. Mol. Biomark. 16, 229-233 (2012).

186. Nakayama, E. E., Tanaka, Y., Nagai, Y., Iwamoto, A. \& Shioda, T. A CCR2-V64I polymorphism affects stability of CCR2A isoform. AIDS 18, 729-738 (2004).

187. Cho, Y. A. \& Kim, J. Association of polymorphisms in the MCP-1 and CCR2 genes with the risk of cancer: a meta-analysis. Cytokine 64, 213-220 (2013).

188. Huang, Y. et al. Relationship between CCR2-V64I polymorphism and cancer risk: a meta-analysis. Gene 524, 54-58 (2013).

189. Hoshino, A. et al. Roles of chemokine receptor CX3CR1 in maintaining murine bone homeostasis through the regulation of both osteoblasts and osteoclasts. J. Cell Sci. 126, 1032-1045 (2013).

190. Goncalves-Zillo, T. O. et al. Increased bone loss and amount of osteoclasts in kinin B1 receptor knockout mice. J. Clin. Periodontol. 40, 653-660 (2013).

191. Hoshino, A. et al. Deficiency of chemokine receptor CCR1 causes osteopenia due to impaired functions of osteoclasts and osteoblasts. J. Biol. Chem. 285, 28826-28837 (2010).

192. Taddei, S. R. et al. The effect of CCL3 and CCR1 in bone remodeling induced by mechanical loading during orthodontic tooth movement in mice. Bone $\mathbf{5 2}$ 259-267 (2013).

193. Doucet, M. et al. CCL20/CCR6 signaling regulates bone mass accrual in mice. J. Bone Miner. Res. 31, 1381-1390 (2016).

194. Zhao, H. et al. Chemokine-like receptor 1 deficiency leads to lower bone mass in male mice. Cell. Mol. Life Sci. 76, 355-367 (2019).
195. Zhu, W., Liang, G., Huang, Z., Doty, S. B. \& Boskey, A. L. Conditional inactivation of the CXCR4 receptor in osteoprecursors reduces postnatal bone formation due to impaired osteoblast development. J. Biol. Chem. 286, 26794-26805 (2011).

196. Li, J. et al. Investigation of bioeffects of $\mathrm{G}$ protein-coupled receptor 1 on bone turnover in male mice. J. Orthop. Transl. 10, 42-51 (2017).

197. Brommage, R. et al. High-throughput screening of mouse gene knockouts identifies established and novel skeletal phenotypes. Bone Res. 2, 14034 (2014).

198. Bohlooly, Y. M. et al. Osteoporosis in MCHR1-deficient mice. Biochem. Biophys. Res. Commun. 318, 964-969 (2004).

199. Xing, Z. et al. Multiple roles for CCR2 during fracture healing. Dis. Model Mech. 3, 451-458 (2010).

200. Kawakami, Y. et al. SDF-1/CXCR4 axis in Tie2-lineage cells including endothelial progenitor cells contributes to bone fracture healing. J. Bone Miner. Res. 30, 95-105 (2015).

201. Jacobs, J. P. et al. Deficiency of CXCR2, but not other chemokine receptors, attenuates autoantibody-mediated arthritis in a murine model. Arthritis Rheum. 62, 1921-1932 (2010).

202. Murakoshi, M. et al. Discovery and pharmacological effects of a novel GPR142 antagonist. J. Recept. Signal. Transduct. Res. 37, 290-296 (2017).

203. Mader, T. L. et al. CCR2 elimination in mice results in larger and stronger tibial bones but bone loss is not attenuated following ovariectomy or muscle denervation. Calcif. Tissue Int. 95, 457-466 (2014).

204. Takebe, K., Rai, M. F., Schmidt, E. J. \& Sandell, L. J. The chemokine receptor CCR5 plays a role in post-traumatic cartilage loss in mice, but does not affect synovium and bone. Osteoarthritis Cartilage 23, 454-461 (2015).

205. Andrade, I. et al. CCR5 down-regulates osteoclast function in orthodontic tooth movement. J. Dent. Res. 88, 1037-1041 (2009).

206. Sambamurthy, N. et al. Chemokine receptor-7 (CCR7) deficiency leads to delayed development of joint damage and functional deficits in a murine model of osteoarthritis. J. Orthop. Res. 36, 864-875 (2018).

207. Soriano-Guillen, L. et al. Adult height after ketoconazole treatment in patients with familial male-limited precocious puberty. J. Clin. Endocrinol. Metab. 90, 147-151 (2005).

208. Bertelloni, S. et al. Long-term outcome of male-limited gonadotropin-independent precocious puberty. Horm. Res. 48, 235-239 (1997).

209. Shenker, A. et al. A constitutively activating mutation of the luteinizing hormone receptor in familial male precocious puberty. Nature 365, 652-654 (1993).

210. Rendina, D. et al. FSHR gene polymorphisms influence bone mineral density and bone turnover in postmenopausal women. Eur. J. Endocrinol. 163, 165-172 (2010).

211. Ferlin, A. et al. Mutations in the insulin-like factor 3 receptor are associated with osteoporosis. J. Bone Miner. Res. 23, 683-693 (2008).

212. Liu, R. D. et al. The Glu727 allele of thyroid stimulating hormone receptor gene is associated with osteoporosis. N. Am. J. Med. Sci. 4, 300-304 (2012).

213. Orozco, G. et al. HLA-DPB1-COL11A2 and three additional XMHC loci are independently associated with RA in a UK cohort. Genes Immun. 12, 169-175 (2011).

214. Styrkarsdottir, U. et al. Nonsense mutation in the LGR4 gene is associated with several human diseases and other traits. Nature 497, 517-520 (2013).

215. Ferlin, A. et al. New roles for INSL3 in adults. Ann. NY Acad. Sci. 1160, 215-218 (2009).

216. van der Deure, W. M. et al. Effects of serum TSH and FT4 levels and the TSHRAsp727Glu polymorphism on bone: the Rotterdam Study. Clin. Endocrinol. 68, 175-181 (2008).

217. Gwinn, M. R., Sharma, A. \& De Nardin, E. Single nucleotide polymorphisms of the $\mathrm{N}$-formyl peptide receptor in localized juvenile periodontitis. J. Periodontol. 70, 1194-1201 (1999).

218. Sun, P. et al. Loss of Lgr4 inhibits differentiation, migration and apoptosis, and promotes proliferation in bone mesenchymal stem cells. J. Cell. Physiol. 234, 10855-10867 (2019)

219. Zhu, C. et al. LGR4 acts as a key receptor for R-spondin 2 to promote osteogenesis through Wnt signaling pathway. Cell. Signal. 28, 989-1000 (2016).

220. Whyte, L. S. et al. The putative cannabinoid receptor GPR55 affects osteoclast function in vitro and bone mass in vivo. Proc. Natl Acad. Sci. USA 106, 16511-16516 (2009).

221. Krieger, N. S. et al. Increased bone density in mice lacking the proton receptor OGR1. Kidney Int. 89, 565-573 (2016).

222. Orriss, I. R. et al. The P2Y(6) receptor stimulates bone resorption by osteoclasts. Endocrinology 152, 3706-3716 (2011).

223. Hikiji, H. et al. TDAG8 activation inhibits osteoclastic bone resorption. FASEB J. 28, 871-879 (2014)

224. Baribault, H. et al. The G-protein-coupled receptor GPR103 regulates bone formation. Mol. Cell. Biol. 26, 709-717 (2006).

225. Orriss, I. et al. Bone phenotypes of P2 receptor knockout mice. Front. Biosci. (Sch. Ed.) 3, 1038-1046 (2011). 
226. Su, X. et al. The ADP receptor P2RY12 regulates osteoclast function and pathologic bone remodeling. J. Clin. Invest. 122, 3579-3592 (2012).

227. Francis, N. et al. Keratinocyte-specific ablation of protease-activated receptor 2 prevents gingival inflammation and bone loss in a mouse model of periodontal disease. Cell Microbiol. 20, e12891 (2018).

228. Hoebertz, A., Meghji, S., Burnstock, G. \& Arnett, T. R. Extracellular ADP is a powerful osteolytic agent: evidence for signaling through the P2Y(1) receptor on bone cells. FASEB J. 15, 1139-1148 (2001).

229. Wang, N., Robaye, B., Gossiel, F., Boeynaems, J. M. \& Gartland, A. The P2Y13 receptor regulates phosphate metabolism and FGF-23 secretion with effects on skeletal development. FASEB J. 28, 2249-2259 (2014).

230. Ferrell, W. R. et al. Essential role for proteinase-activated receptor-2 in arthritis. J. Clin. Invest. 111, 35-41 (2003).

231. Wang, N. et al. Reduced bone turnover in mice lacking the P2Y13 receptor of ADP. Mol. Endocrinol. 26, 142-152 (2012).

232. Orriss, I. R. et al. Activation of the $\mathrm{P} 2 \mathrm{Y} 2$ receptor regulates bone cell function by enhancing ATP release. J. Endocrinol. 233, 341-356 (2017).

233. Xing, $\mathrm{Y}$. et al. The roles of $\mathrm{P} 2 \mathrm{Y} 2$ purinergic receptors in osteoblasts and mechanotransduction. PLOS ONE 9, e108417 (2014).

234. Ke, H. Z. et al. Deletion of the P2X7 nucleotide receptor reveals its regulatory roles in bone formation and resorption. Mol. Endocrinol. 17, 1356-1367 (2003)

235. Gartland, A. et al. Multinucleated osteoclast formation in vivo and in vitro by P2X7 receptor-deficient mice. Crit. Rev. Eukaryot. Gene Expr. 13, 243-253 (2003).

236. Bjarnadottir, T. K. et al. The human and mouse repertoire of the adhesion family of G-protein-coupled receptors. Genomics 84, 23-33 (2004).

237. Harmar, A. J. Family-B G-protein-coupled receptors. Genome Biol. 2, REVIEWS3013 (2001)

238. Kwakkenbos, M. J. et al. The EGF-TM7 family: a postgenomic view. Immunogenetics 55, 655-666 (2004).

239. Stacey, M., Lin, H. H., Gordon, S. \& McKnight, A. J. LNB-TM7, a group of seventransmembrane proteins related to family-B G-protein-coupled receptors. Trends Biochem. Sci. 25, 284-289 (2000).

240. Hamann, J. et al. International Union of Basic and Clinical Pharmacology. XCIV. Adhesion G protein-coupled receptors. Pharmacol. Rev. 67, 338-367 (2015).

241. Bjarnadottir, T. K., Fredriksson, R. \& Schioth, H. B. The adhesion GPCRs: a unique family of $G$ protein-coupled receptors with important roles in both central and peripheral tissues. Cell. Mol. Life Sci. 64, 2104-2119 (2007).

242. Krasnoperov, V. G. et al. alpha-latrotoxin stimulates exocytosis by the interaction with a neuronal G-protein-coupled receptor. Neuron 18, 925-937 (1997).

243. Lin, H. H. et al. Autocatalytic cleavage of the EMR2 receptor occurs at a conserved G protein-coupled receptor proteolytic site motif. J. Biol. Chem. 279, 31823-31832 (2004).

244. Arac, D. et al. A novel evolutionarily conserved domain of cell-adhesion GPCRs mediates autoproteolysis. EMBO J. 31, 1364-1378 (2012).

245. Promel, S., Langenhan, T. \& Arac, D. Matching structure with function: the GAIN domain of adhesion-GPCR and PKD1-like proteins. Trends Pharmacol. Sci. 34, 470-478 (2013).

246. Langenhan, T. et al. Latrophilin signaling links anterior-posterior tissue polarity and oriented cell divisions in the C. elegans embryo. Dev. Cell 17, 494-504 (2009).

247. Langenhan, T., Aust, G. \& Hamann, J. Sticky signaling-adhesion class G proteincoupled receptors take the stage. Sci. Signal. 6, re3 (2013).

248. Ikegawa, S. Genomic study of adolescent idiopathic scoliosis in Japan. Scoliosis Spinal Dis. 11, 5 (2016).

249. Kim, J. J. et al. Exome sequencing and subsequent association studies identify five amino acid-altering variants influencing human height. Hum. Genet. 131, 471-478 (2012).

250. Qin, X. D. et al. Genetic variant of GPR126 gene is functionally associated with adolescent idiopathic scoliosis in Chinese Population. Spine 42, E1098-E1103 (2017).

251. Giampietro, P. F. SNPping away at the genetic basis of adolescent idiopathic scoliosis. Ann. Transl. Med. 3(Suppl. 1), 1-4 (2015).

252. $\mathrm{Xu}, \mathrm{J}$. F. et al. Association of GPR126 gene polymorphism with adolescent idiopathic scoliosis in Chinese populations. Genomics 105, 101-107 (2015).

253. Kou, I. et al. Genetic variants in GPR126 are associated with adolescent idiopathic scoliosis. Nat. Genet. 45, 676-679 (2013).

254. Karnik, S. S. et al. International Union of Basic and Clinical Pharmacology. XCIX. Angiotensin Receptors: Interpreters of Pathophysiological Angiotensinergic Stimuli [corrected]. Pharmacol. Rev. 67, 754-819 (2015).

255. Liebscher, I., Schoneberg, T. \& Promel, S. Progress in demystification of adhesion G protein-coupled receptors. Biol. Chem. 394, 937-950 (2013).

256. Liu, J. Z. et al. Genome-wide association study of height and body mass index in Australian twin families. Twin Res. Hum. Genet. 13, 179-193 (2010).

257. Soranzo, N. et al. Meta-analysis of genome-wide scans for human adult stature identifies novel Loci and associations with measures of skeletal frame size. PLoS Genet. 5, e1000445 (2009).
258. Ravenscroft, G. et al. Mutations of GPR126 are responsible for severe arthrogryposis multiplex congenita. Am. J. Hum. Genet. 96, 955-961 (2015).

259. Kitagaki, J. et al. A putative association of a single nucleotide polymorphism in GPR126 with aggressive periodontitis in a Japanese population. PLOS ONE 11, e0160765 (2016).

260. Tseng, W. Y. et al. High levels of soluble GPR56/ADGRG1 are associated with positive rheumatoid factor and elevated tumor necrosis factor in patients with rheumatoid arthritis. J. Microbiol. Immunol. Infect. 51, 485-491 (2018).

261. Chen, Z. G., Gao, P. J. \& Li, Z. P. Expression of G protein-coupled receptor 56 is an unfavorable prognostic factor in osteosarcoma patients. Tohoku J. Exp. Med. 239, 203-211 (2016).

262. Liu, Z. Q., Zhang, G. R., Zhao, C. L. \& Li, J. M. Clinical significance of G proteincoupled receptor 110 (GPR110) as a novel prognostic biomarker in osteosarcoma. Med. Sci. Monit. 24, 5216-5224 (2018).

263. Tonjes, A. et al. Genetic variation in GPR133 is associated with height: genome wide association study in the self-contained population of Sorbs. Hum. Mol. Genet. 18, 4662-4668 (2009).

264. Kim, Y. K. et al. Gene-based copy number variation study reveals a microdeletion at 12q24 that influences height in the Korean population. Genomics 101, 134-138 (2013)

265. Karner, C. M., Long, F., Solnica-Krezel, L., Monk, K. R. \& Gray, R. S. Gpr126/Adgrg6 deletion in cartilage models idiopathic scoliosis and pectus excavatum in mice. Hum. Mol. Genet. 24, 4365-4373 (2015).

266. Yeon Won, H., Hwan Mun, S., Shin, B. \& Lee, S. K. Contradictory role of CD97 in basal and tumor necrosis factor-induced osteoclastogenesis in vivo. Arthritis Rheum. 68, 1301-1313 (2016).

267. Hoek, R. M. et al. Deletion of either CD55 or CD97 ameliorates arthritis in mouse models. Arthritis Rheum. 62, 1036-1042 (2010).

268. Bjarnadottir, T. K. et al. Comprehensive repertoire and phylogenetic analysis of the $\mathrm{G}$ protein-coupled receptors in human and mouse. Genomics 88, 263-273 (2006).

269. Nordstrom, K. J., Fredriksson, R. \& Schioth, H. B. The amphioxus (Branchiostoma floridae) genome contains a highly diversified set of $\mathrm{G}$ protein-coupled receptors. BMC Evol. Biol. 8, 9 (2008).

270. Lagerstrom, M. C. et al. The G protein-coupled receptor subset of the chicken genome. PLoS Comput. Biol. 2, e54 (2006).

271. Katanaev, V. L. The Wnt/Frizzled GPCR signaling pathway. Biochemistry (Mosc.) 75, 1428-1434 (2010)

272. Logan, C. Y. \& Nusse, R. The Wnt signaling pathway in development and disease. Annu. Rev. Cell Dev. Biol. 20, 781-810 (2004).

273. Wang, Y., Chang, H., Rattner, A. \& Nathans, J. Frizzled receptors in development and disease. Curr. Top. Dev. Biol. 117, 113-139 (2016).

274. Lagerstrom, M. C. \& Schioth, H. B. Structural diversity of G protein-coupled receptors and significance for drug discovery. Nat. Rev. Drug Discov. 7, 339-357 (2008).

275. Kamesh, N., Aradhyam, G. K. \& Manoj, N. The repertoire of G protein-coupled receptors in the sea squirt Ciona intestinalis. BMC Evol. Biol. 8, 129 (2008).

276. Huang, H. C. \& Klein, P. S. The Frizzled family: receptors for multiple signal transduction pathways. Genome Biol. 5, 234 (2004).

277. Vinson, C. R., Conover, S. \& Adler, P. N. A Drosophila tissue polarity locus encodes a protein containing seven potential transmembrane domains. Nature 338, 263-264 (1989).

278. Kuhn, C., Bufe, B., Batram, C. \& Meyerhof, W. Oligomerization of TAS2R bitter taste receptors. Chem. Senses 35, 395-406 (2010).

279. Sugawara, T. et al. Diversification of bitter taste receptor gene family in western chimpanzees. Mol. Biol. Evol. 28, 921-931 (2011).

280. Wang, X. X., Thomas, S. D. \& Zhang, J. Z. Relaxation of selective constraint and loss of function in the evolution of human bitter taste receptor genes. Hum. Mol. Genet. 13, 2671-2678 (2004).

281. Kim, U., Wooding, S., Ricci, D., Jorde, L. B. \& Drayna, D. Worldwide haplotype diversity and coding sequence variation at human bitter taste receptor loci. Hum. Mutat. 26, 199-204 (2005).

282. Zhang, Y. et al. Functional and association analysis of frizzled 1 (FZD1) promoter haplotypes with femoral neck geometry. Bone 46, 1131-1137 (2010).

283. Yerges, L. M. et al. Functional characterization of genetic variation in the Frizzled 1 (FZD1) promoter and association with bone phenotypes: more to the LRP5 story? J. Bone Miner. Res. 24, 87-96 (2009).

284. Frojmark, A. S. et al. Mutations in Frizzled 6 cause isolated autosomal-recessive nail dysplasia. Am. J. Hum. Genet. 88, 852-860 (2011).

285. Wilson, N. J. et al. Recessive mutations in the gene encoding frizzled 6 cause twenty nail dystrophy-expanding the differential diagnosis for pachyonychia congenita. J. Dermatol. Sci. 70, 58-60 (2013).

286. Naz, G. et al. FZD6 encoding the Wnt receptor frizzled 6 is mutated in autosomal-recessive nail dysplasia. Br. J. Dermatol 166, 1088-1094 (2012). 
287. Francke, U. Williams-Beuren syndrome: genes and mechanisms. Hum. Mol. Genet. 8, 1947-1954 (1999).

288. Albers, J. et al. Control of bone formation by the serpentine receptor Frizzled-9. J. Cell Biol. 192, 1057-1072 (2011).

289. Heilmann, A. et al. The Wnt serpentine receptor Frizzled-9 regulates new bone formation in fracture healing. PLOS ONE 8, 12 (2013).

290. Wang, Q., Huang, C., Zeng, F., Xue, M. \& Zhang, X. Activation of the Hh pathway in periosteum-derived mesenchymal stem cells induces bone formation in vivo: implication for postnatal bone repair. Am. J. Pathol. 177, 3100-3111 (2010).

291. Di Paolo, E. et al. Role of charged amino acids conserved in the vasoactive intestinal polypeptide/secretin family of receptors on the secretin receptor functionality. Peptides 20, 1187-1193 (1999).

292. Segre, G. V. \& Goldring, S. R. Receptors for secretin, calcitonin, parathyroid hormone (PTH)/PTH-related peptide, vasoactive intestinal peptide, glucagonlike peptide 1, growth hormone-releasing hormone, and glucagon belong to a newly discovered G-protein-linked receptor family. Trends Endocrinol. Metab. 4, 309-314 (1993).

293. Holtmann, M. H., Ganguli, S., Hadac, E. M., Dolu, V. \& Miller, L. J. Multiple extracellular loop domains contribute critical determinants for agonist binding and activation of the secretin receptor. J. Biol. Chem. 271, 14944-14949 (1996).

294. Dong, M., Wang, Y., Pinon, D. I., Hadac, E. M. \& Miller, L. J. Demonstration of a direct interaction between residue 22 in the carboxyl-terminal half of secretin and the amino-terminal tail of the secretin receptor using photoaffinity labeling. J. Biol. Chem. 274, 903-909 (1999).

295. Gourlet, P. et al. Interaction of amino acid residues at positions 8-15 of secretin with the N-terminal domain of the secretin receptor. Eur. J. Biochem. 239, 349-355 (1996).

296. Vilardaga, J. P. et al. Mutational analysis of extracellular cysteine residues of rat secretin receptor shows that disulfide bridges are essential for receptor function. Eur. J. Biochem. 246, 173-180 (1997).

297. Dong, M., Gao, F., Pinon, D. I. \& Miller, L. J. Insights into the structural basis of endogenous agonist activation of family B G protein-coupled receptors. Mol. Endocrinol. 22, 1489-1499 (2008).

298. Furness, S. G., Wootten, D., Christopoulos, A. \& Sexton, P. M. Consequences of splice variation on Secretin family $G$ protein-coupled receptor function. Br. J. Pharmacol. 166, 98-109 (2012).

299. Zupan, J., Komadina, R. \& Marc, J. The relationship between osteoclastogenic and anti-osteoclastogenic pro-inflammatory cytokines differs in human osteoporotic and osteoarthritic bone tissues. J. Biomed. Sci. 19, 28 (2012).

300. Zmuda, J. M. et al. Genetic analysis of vertebral trabecular bone density and cross-sectional area in older men. Osteoporos. Int. 22, 1079-1090 (2011).

301. Lee, H. J. et al. Fracture, bone mineral density, and the effects of calcitonin receptor gene in postmenopausal Koreans. Osteoporos. Int. 21, 1351-1360 (2010).

302. Masi, L. et al. Polymorphisms of the calcitonin receptor gene are associated with bone mineral density in postmenopausal Italian women. Biochem. Biophys. Res. Commun. 248, 190-195 (1998).

303. Zofkova, I., Zajickova, K., Hill, M. \& Krepelova, A. Does polymorphism C1377T of the calcitonin receptor gene determine bone mineral density in postmenopausal women? Exp. Clin. Endocrinol. Diabetes 111, 447-449 (2003).

304. Kang, B. Y., Kim, J. Y. \& Lee, K. O. Association between an Alul polymorphism in the calcitonin receptor gene and quantitative ultrasound parameters in Korean men. Med. Princ. Pract. 16, 389-393 (2007).

305. Tsai, F. J., Chen, W. C., Chen, H. Y. \& Tsai, C. H. The ALUI calcitonin receptor gene polymorphism (TT) is associated with low bone mineral density and susceptibility to osteoporosis in postmenopausal women. Gynecol. Obstet. Invest. 55, 82-87 (2003)

306. Taboulet, J. et al. Calcitonin receptor polymorphism is associated with a decreased fracture risk in post-menopausal women. Hum. Mol. Genet. 7, 2129-2133 (1998).

307. Dacquin, R. et al. Amylin inhibits bone resorption while the calcitonin receptor controls bone formation in vivo. J. Cell Biol. 164, 509-514 (2004).

308. Rivadeneira, F. et al. Twenty bone-mineral-density loci identified by large-scale meta-analysis of genome-wide association studies. Nat. Genet. 41, 1199-1206 (2009).

309. Aguiar-Oliveira, M. H. et al. Older individuals heterozygous for a growth hormone-releasing hormone receptor gene mutation are shorter than normal subjects. J. Hum. Genet. 60, 335-338 (2015).

310. Camats, N. et al. Contribution of human growth hormone-releasing hormone receptor (GHRHR) gene sequence variation to isolated severe growth hormone deficiency (ISGHD) and normal adult height. Clin. Endocrinol. (Oxf.) 77, 564-574 (2012).

311. Inoue, $\mathrm{H}$. et al. Identification and functional analysis of novel human growth hormone-releasing hormone receptor (GHRHR) gene mutations in Japanese subjects with short stature. Clin. Endocrinol. 74, 223-233 (2011).
312. Martari, M. \& Salvatori, R. Diseases associated with growth hormone-releasing hormone receptor (GHRHR) mutations. Prog. Mol. Biol. Transl. Sci. 88, 57-84 (2009).

313. Wang, Q. et al. Identification of a novel splicing mutation in the growth hormone (GH)-releasing hormone receptor gene in a Chinese family with pituitary dwarfism. Mol. Cell. Endocrinol. 313, 50-56 (2009).

314. Oliveira, C. R. P. et al. Sizes of abdominal organs in adults with severe short stature due to severe, untreated, congenital GH deficiency caused by a homozygous mutation in the GHRH receptor gene. Clin. Endocrinol. 69, 153-158 (2008).

315. Salvatori, R. et al. Familial dwarfism due to a novel mutation of the growth hormone-releasing hormone receptor gene. J. Clin. Endocr. Metab. 84, 917-923 (1999).

316. Baumann, G. Mutations in the growth hormone releasing hormone receptor: a new form of dwarfism in humans. Growth Horm. IGF Res. 9(Suppl. B), 24-29; discussion 29-30 (1999).

317. Baumann, G. \& Maheshwari, H. The Dwarfs of Sindh: severe growth hormone (GH) deficiency caused by a mutation in the GH-releasing hormone receptor gene. Acta Paediatr. 86, 33-38 (1997).

318. Wajnrajch, M. P., Gertner, J. M., Harbison, M. D., Chua, S. C. \& Leibel, R. L. Nonsense mutation in the human growth hormone-releasing hormone receptor causes growth failure analogous to the little (lit) mouse. Nat. Genet. 12, 88-90 (1996).

319. Harsloef, T. et al. A functional amino acid substitution in the glucose-dependent insulinotropic polypeptide-receptor (GIPR) gene is associated with bone mineral density, bone loss, and osteoporotic fractures: The Danish Osteoporosis Prevention Study. J. Bone Miner. Res. 28 (Suppl. 1), 138-139 (2013).

320. Torekov, S. S. et al. A functional amino acid substitution in the glucosedependent insulinotropic polypeptide receptor (GIPR) gene is associated with lower bone mineral density and increased fracture risk. J. Clin. Endocr. Metab. 99, E729-E733 (2014).

321. Scillitani, A., Jang, C., Wong, B. Y. L., Hendy, G. N. \& Cole, D. E. C. A functional polymorphism in the PTHR1 promoter region is associated with adult height and BMD measured at the femoral neck in a large cohort of young caucasian women. Hum. Genet. 119, 416-421 (2006).

322. Zhang, Y. Y. et al. Tests of linkage and association of PTH/PTHrP receptor type 1 gene with bone mineral density and height in Caucasians. J. Bone Miner. Metab. 24, 36-41 (2006)

323. Vilarino-Guell, $C$. et al. PTHR1 polymorphisms influence BMD variation through effects on the growing skeleton. Calcif. Tissue Int. 81, 270-278 (2007).

324. Wynne, F. et al. Suggestive linkage of 2p22-25 and 11q12-13 with low bone mineral density at the lumbar spine in the Irish population. Calcif. Tissue Int. 72, 651-658 (2003).

325. Schipani, E. \& Provot, S. PTHrP, PTH, and the PTH/PTHrP receptor in endochondral bone development. Birth. Defects Res. C Embryo. Today 69, 352-362 (2003).

326. Karaplis, A. C. et al. Inactivating mutation in the human parathyroid hormone receptor type 1 gene in Blomstrand chondrodysplasia. Endocrinology 139, 5255-5258 (1998).

327. Lanske, B. et al. PTH/PTHrP receptor in early development and Indian hedgehog-regulated bone growth. Science 273, 663-666 (1996).

328. Hirai, T. et al. Bone is a major target of PTH/PTHrP receptor signaling in regulation of fetal blood calcium homeostasis. Endocrinology 156, 2774-2780 (2015).

329. Qiu, T. et al. PTH receptor signaling in osteoblasts regulates endochondral vascularization in maintenance of postnatal growth plate. J. Bone Miner. Res. 30, 309-317 (2015).

330. Guo, J., Chung, U., Kondo, H., Bringhurst, F. R. \& Kronenberg, H. M. The PTH/ PTHrP receptor can delay chondrocyte hypertrophy in vivo without activating phospholipase C. Dev. Cell 3, 183-194 (2002).

331. Lanske, B. et al. The parathyroid hormone (PTH)/PTH-related peptide receptor mediates actions of both ligands in murine bone. Endocrinology 139, 5194-5204 (1998).

332. Karperien, M. et al. A frame-shift mutation in the type I parathyroid hormone (PTH)/PTH-related peptide receptor causing Blomstrand lethal osteochondrodysplasia. J. Clin. Endocrinol. Metab. 84, 3713-3720 (1999).

333. Hopyan, S. et al. A mutant PTH/PTHrP type I receptor in enchondromatosis. Nat. Genet. 30, 306-310 (2002).

334. Powell, W. F. et al. Targeted ablation of the PTH/PTHrP receptor in osteocytes impairs bone structure and homeostatic calcemic responses. J. Endocrinol. 209, 21-32 (2011).

335. Qiu, T. et al. IGF-I induced phosphorylation of PTH receptor enhances osteoblast to osteocyte transition. Bone Res. 6, 5 (2018).

336. Qiu, T. et al. TGF-beta type II receptor phosphorylates PTH receptor to integrate bone remodelling signalling. Nat. Cell Biol. 12, 224-234 (2010). 
337. Dempster, D. W., Cosman, F., Parisien, M., Shen, V. \& Lindsay, R. Anabolic actions of parathyroid hormone on bone. Endocr. Rev. 14, 690-709 (1993).

338. Iwata, A., Kanayama, M., Oha, F., Hashimoto, T. \& Iwasaki, N. Effect of teriparatide (rh-PTH 1-34) versus bisphosphonate on the healing of osteoporotic vertebral compression fracture: a retrospective comparative study. BMC Musculoskelet. Disord. 18, 148 (2017).

339. Lu, R. et al. Parathyroid hormone administration improves bone marrow microenvironment and partially rescues haematopoietic defects in Bmi1-null mice. PLOS ONE 9, e93864 (2014).

340. Balani, D. H., Ono, N. \& Kronenberg, H. M. Parathyroid hormone regulates fates of murine osteoblast precursors in vivo. J. Clin. Invest. 127, 3327-3338 (2017).

341. Zheng, L. et al. Ciliary parathyroid hormone signaling activates transforming growth factor-beta to maintain intervertebral disc homeostasis during aging. Bone Res. 6, 21 (2018).

342. Xie, D. et al. Glucose-dependent insulinotropic polypeptide receptor knockout mice have altered bone turnover. Bone 37, 759-769 (2005).

343. Yamada, $C$. et al. The murine glucagon-like peptide-1 receptor is essential for control of bone resorption. Endocrinology 149, 574-579 (2008).

344. Tsukiyama, K. et al. Gastric inhibitory polypeptide as an endogenous factor promoting new bone formation after food ingestion. Mol. Endocrinol. 20, 1644-1651 (2006).

345. Shen, W. R. et al. The glucagon-like peptide- 1 receptor agonist exendin- 4 inhibits lipopolysaccharide-induced osteoclast formation and bone resorption via inhibition of TNF-alpha expression in macrophages. J. Immunol. Res. 2018 5783639 (2018).

346. Kerkhof, H. J. et al. A genome-wide association study identifies an osteoarthritis susceptibility locus on chromosome 7q22. Arthritis Rheum. 62, 499-510 (2010).

347. Verleyen, D., Luyten, F. P. \& Tylzanowski, P. Orphan G-protein coupled receptor 22 (Gpr22) regulates cilia length and structure in the zebrafish Kupffer's vesicle. PLOS ONE 9, e110484 (2014).

348. Banziger, C. et al. Wntless, a conserved membrane protein dedicated to the secretion of Wnt proteins from signaling cells. Cell 125, 509-522 (2006).

349. Matsuda, A. et al. Large-scale identification and characterization of human genes that activate NF-kappa B and MAPK signaling pathways. Oncogene 22, 3307-3318 (2003).

350. Deng, Y. H. et al. The influence of the genetic and non-genetic factors on bone mineral density and osteoporotic fractures in Chinese women. Endocrine 43, 127-135 (2013).

351. Roshandel, D. et al. Polymorphisms in genes involved in the NF-kappa B signalling pathway are associated with bone mineral density, geometry and turnover in men. PLOS ONE 6, e28031 (2011).

352. Styrkarsdottir, U. et al. European bone mineral density loci are also associated with BMD in East-Asian populations. PLoS ONE 5, e13217 (2010).

353. Hsu, Y. H. et al. An integration of genome-wide association study and gene expression profiling to prioritize the discovery of novel susceptibility Loci for osteoporosis-related traits. PLoS Genet. 6, e1000977 (2010).

354. Zhong, Z. et al. Wntless functions in mature osteoblasts to regulate bone mass. Proc. Natl Acad. Sci. USA 109, E2197-E2204 (2012).

355. Zhong, Z. A. et al. Wntless spatially regulates bone development through betacatenin-dependent and independent mechanisms. Dev. Dyn. 244, 1347-1355 (2015).

356. Jovanovic, M. et al. Perturbed bone composition and integrity with disorganized osteoblast function in zinc receptor/Gpr39-deficient mice. FASEB J. 32 2507-2518 (2018)

357. Bologa, C. G. et al. Virtual and biomolecular screening converge on a selective agonist for GPR30. Nat. Chem. Biol. 2, 207-212 (2006).

358. Filardo, E. J., Quinn, J. A., Frackelton, A. R. Jr. \& Bland, K. I. Estrogen action via the G protein-coupled receptor, GPR30: stimulation of adenylyl cyclase and cAMPmediated attenuation of the epidermal growth factor receptor-to-MAPK signaling axis. Mol. Endocrinol. 16, 70-84 (2002).
359. Funakoshi, T., Yanai, A., Shinoda, K., Kawano, M. M. \& Mizukami, Y. G proteincoupled receptor 30 is an estrogen receptor in the plasma membrane. Biochem. Biophys. Res. Commun. 346, 904-910 (2006).

360. Filardo, E. et al. Activation of the novel estrogen receptor $\mathrm{G}$ protein-coupled receptor 30 (GPR30) at the plasma membrane. Endocrinology 148, 3236-3245 (2007).

361. Revankar, C. M. et al. Synthetic estrogen derivatives demonstrate the functionality of intracellular GPR30. ACS Chem. Biol. 2, 536-544 (2007).

362. Heino, T. J., Chagin, A. S. \& Savendahl, L. The novel estrogen receptor G-proteincoupled receptor 30 is expressed in human bone. J. Endocrinol. 197, R1-R6 (2008).

363. Teplyuk, N. M. et al. Runx2 regulates $G$ protein-coupled signaling pathways to control growth of osteoblast progenitors. J. Biol. Chem. 283, 27585-27597 (2008).

364. Martensson, U. E. et al. Deletion of the $G$ protein-coupled receptor 30 impairs glucose tolerance, reduces bone growth, increases blood pressure, and eliminates estradiol-stimulated insulin release in female mice. Endocrinology 150, 687-698 (2009).

365. Pacheco-Pantoja, E. L., Ranganath, L. R., Gallagher, J. A., Wilson, P. J. \& Fraser, W. $D$. Receptors and effects of gut hormones in three osteoblastic cell lines. $B M C$ Physiol. 11, 12 (2011).

366. Popovics, P. \& Stewart, A. J. GPR39: a $\mathrm{Zn}(2+)$-activated G protein-coupled receptor that regulates pancreatic, gastrointestinal and neuronal functions. Cell. Mol. Life Sci. 68, 85-95 (2011).

367. Briscoe, C. P. et al. The orphan G protein-coupled receptor GPR40 is activated by medium and long chain fatty acids. J. Biol. Chem. 278, 11303-11311 (2003).

368. Itoh, Y. et al. Free fatty acids regulate insulin secretion from pancreatic beta cells through GPR40. Nature 422, 173-176 (2003).

369. Kotarsky, K., Nilsson, N. E., Olde, B. \& Owman, C. Improved reporter gene assays used to identify ligands acting on orphan seven-transmembrane receptors. Pharmacol. Toxicol. 93, 249-258 (2003).

370. Latour, M. G. et al. GPR40 is necessary but not sufficient for fatty acid stimulation of insulin secretion in vivo. Diabetes 56, 1087-1094 (2007).

371. Nilsson, N. E., Kotarsky, K., Owman, C. \& Olde, B. Identification of a free fatty acid receptor, FFA2R, expressed on leukocytes and activated by short-chain fatty acids. Biochem. Biophys. Res. Commun. 303, 1047-1052 (2003).

372. Oh, D. Y. et al. GPR120 is an omega-3 fatty acid receptor mediating potent antiinflammatory and insulin-sensitizing effects. Cell 142, 687-698 (2010).

373. Cornish, J. et al. Modulation of osteoclastogenesis by fatty acids. Endocrinology 149, 5688-5695 (2008).

374. Mieczkowska, A., Basle, M. F., Chappard, D. \& Mabilleau, G. Thiazolidinediones induce osteocyte apoptosis by a $\mathrm{G}$ protein-coupled receptor 40-dependent mechanism. J. Biol. Chem. 287, 23517-23526 (2012).

375. Monfoulet, L. E., Philippe, C., Mercier, S., Coxam, V. \& Wittrant, Y. Deficiency of Gprotein coupled receptor 40 , a lipid-activated receptor, heightens in vitro- and in vivo-induced murine osteoarthritis. Exp. Biol. Med. (Maywood) 240, 854-866 (2015).

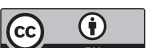

Open Access This article is licensed under a Creative Commons Attribution 4.0 International License, which permits use, sharing, adaptation, distribution and reproduction in any medium or format, as long as you give appropriate credit to the original author(s) and the source, provide a link to the Creative Commons license, and indicate if changes were made. The images or other third party material in this article are included in the article's Creative Commons license, unless indicated otherwise in a credit line to the material. If material is not included in the article's Creative Commons license and your intended use is not permitted by statutory regulation or exceeds the permitted use, you will need to obtain permission directly from the copyright holder. To view a copy of this license, visit http://creativecommons. org/licenses/by/4.0/.

(c) The Author(s) 2019 